\title{
Effusive crises at Piton de la Fournaise 2014-2015: a review of a multi-national response model
}

\author{
A. J. L. Harris ${ }^{1,2^{*}}$, N. Villeneuve ${ }^{3}$, A. Di Muro ${ }^{3}$, V. Ferrazzini ${ }^{3}$, A. Peltier ${ }^{3}$, D. Coppola ${ }^{4}$, M. Favalli ${ }^{5}$, P. Bachèlery ${ }^{1,2}$, \\ J.-L. Froger ${ }^{1,2}$, L. Gurioli ${ }^{1,2}$, S. Moune ${ }^{1,2}$, I. Vlastélic ${ }^{1,2}$, B. Galle ${ }^{6}$ and S. Arellano ${ }^{6}$
}

\begin{abstract}
Many active European volcanoes and volcano observatories are island-based and located far from their administrative "mainland". Consequently, Governments have developed multisite approaches, in which monitoring is performed by a network of individuals distributed across several national research centers. At a transnational level, multinational networks are also progressively emerging. Piton de la Fournaise (La Réunion Island, France) is one such example. Piton de la Fournaise is one of the most active volcanoes of the World, and is located at the greatest distance from its "mainland" than any other vulnerable "overseas" site, the observatory being $9365 \mathrm{~km}$ from its governing body in Paris. Effusive risk is high, so that a well-coordinated and rapid response involving near-real time delivery of trusted, validated and operational product for hazard assessment is critical. Here we review how near-real time assessments of lava flow propagation were developed using rapid provision, and update, of key source terms through a dynamic and open integration of near-real time remote sensing, modeling and measurement capabilities on both the national and international level. The multi-national system evolved during the five effusive crises of 2014-2015, and is now mature for Piton de la Fournaise. This review allows us to identify strong and weak points in an extended observatory system, and demonstrates that enhanced multi-national integration can have fundamental implications in scientific hazard assessment and response during an on-going effusive crisis.
\end{abstract}

Keywords: Effusive crisis, Volcano observatory, Piton de la Fournaise, Time averaged discharge rates, Lava flow model, Inundation forecasts, Hazard response

\section{Introduction}

When people think of an eruption at a European volcano, they prepare themselves for a damaging event on Vesuvius (e.g., Zuccaro et al. 2008) or a Laki-type event in Iceland (e.g., Schmidt 2015), maybe even an eruption of Etna (e.g., Chester et al. 2008) or Santorini (e.g., Dominey-Howes and Minos-Minopoulos 2004). However, by population number, by far the largest threat is from small island volcanoes beyond the European mainland and the Mediterranean. As we see from Table 1, at-least 27 active European volcanoes are on small

\footnotetext{
* Correspondence: andrew.harris@uca.fr

'Université Clermont Auvergne, CNRS, IRD, OPGC, Laboratoire Magmas et Volcans, F-63000 Clermont-Ferrand, France

${ }^{2}$ Observatoire de Physique du Globe Clermont Ferrand (OPGC), Campus Universitaire des Cézeaux, 4 Avenue Blaise Pascal, TSA 60026 - CS 60026, 63178 Aubière CEDEX, France

Full list of author information is available at the end of the article
}

islands. Of these islands, La Réunion Island (Fig. 1a) is probably the largest with an area of $2510 \mathrm{~km}^{2}$, and dimensions of $71 \mathrm{~km}$ (NW-SE) by $52 \mathrm{~km}$ (NE-SW). On the island no person is further than $57 \mathrm{~km}$ from the active volcanic center: Piton de la Fournaise (Fig. 1b). Although small in a territorial sense, on these islands 3.6 million people live within $30 \mathrm{~km}$ of an active eruptive center, 19 of which have erupted since 1800, with the impacted populations residing at an average distance of $2400 \mathrm{~km}$ from their "mainland" administrative center in continental Europe (Table 1). Of the 27 volcanoes listed in Table 1, 13 (with a total population of 1.1 million) are between 1000 and $2000 \mathrm{~km}$ from their mainland administrative centers, and six (accounting for 0.9 million people) are at distances greater than $5000 \mathrm{~km}$. Of these six, three of the four furthest volcanoes from their mainland administrative centers are French (Table 1). To this 
Table 1 Sub-areal island volcanoes under European governance with historic activity, populations >100 within $30 \mathrm{~km}$ of the active center, and/or eruptions since 1900, as listed by the Smithsonian Institution Global Volcanism Program data base (http://volcano.si.edu/ search_volcano.cfm). Distance from each state capital (Paris, Athens, Rome, The Hague, Oslo, Lisbon and Madrid) was obtained using the world distance calculator of GlobalFeed.com. Last eruption is as of 31/12/2016

\begin{tabular}{|c|c|c|c|c|c|c|}
\hline Volcano & Last eruption & Island & Volcanic Region & Governing Country & Population & Distance $(\mathrm{km})$ \\
\hline Piton de la Fournaise & 2016 & lle de La Réunion & Indian Ocean & France & 246,792 & 9365 \\
\hline The Quill & 250 & Saint Eustatius Island & West Indies & Netherlands & 8361 & 6940 \\
\hline Mount Pelée & 1932 & Martinique & West Indies & France & 382,633 & 6855 \\
\hline Soufrière Guadeloupe & 1977 & Guadeloupe & West Indies & France & 256,899 & 6750 \\
\hline Soufrière Hills & 2013 & Montserrat & West Indies & United Kingdom & 9458 & 6640 \\
\hline Mount Scenery & 1752 & Saba & West Indies & Netherlands & 1640 & 6025 \\
\hline La Palma & 1971 & La Palma Island & Canary Islands & Spain & 55,922 & 1820 \\
\hline Tenerife & 1909 & Tenerife & Canary Islands & Spain & 337,660 & 1750 \\
\hline Fayal & 1958 & Faial & Azores & Portugal & 24,414 & 1690 \\
\hline Santa Barbara & 2000 & Terceira & Azores & Portugal & 55,425 & 1660 \\
\hline San Jorge & 1964 & São Jorge & Azores & Portugal & 16,290 & 1635 \\
\hline Lanzarote & 1824 & Lanzarote & Canary Islands & Spain & 164,123 & 1555 \\
\hline Beerenberg & 1985 & Jan Mayen & Atlantic & Norway & 0 & 1520 \\
\hline Agua de Pau & 1564 & São Miguel & Azores & Portugal & 113,131 & 1445 \\
\hline Picos volcanic system & 1652 & São Miguel & Azores & Portugal & 123,990 & 1445 \\
\hline Sete Cidades & 1880 & São Miguel & Azores & Portugal & 102,848 & 1445 \\
\hline Furnas & 1630 & São Miguel & Azores & Portugal & 87,865 & 1415 \\
\hline Pico & 1720 & Pico Island & Azores & Portugal & 31,521 & 1334 \\
\hline Hierro & 2012 & Hierro Island & Canary Islands & Spain & 20,321 & 1190 \\
\hline Pantelleria & 1891 & Pantelleria & Mediterranean & Italy & 12,403 & 565 \\
\hline Etna & 2016 & Sicily & Mediterranean & Italy & $1,016,540$ & 540 \\
\hline Fossa di Vulcano & 1890 & Vulcano & Mediterranean & Italy & 86,766 & 440 \\
\hline Lipari & 1230 & Lipari & Mediterranean & Italy & 36,059 & 435 \\
\hline Stromboli & 2016 & Stromboli & Mediterranean & Italy & 3894 & 420 \\
\hline Nisyros & 1888 & Nisyros & Aegean Sea & Greece & 14,285 & 345 \\
\hline Nea Kameni & 1950 & Santorini & Aegean Sea & Greece & 12,336 & 235 \\
\hline Ischia & 1302 & Ischia & Mediterranean & Italy & 383,661 & 180 \\
\hline
\end{tabular}

list we can add the sub-marine centers of Mount MacDonald, Mehetia, Mouha Pihaa, Mont Rocard and Tehaitia all of which are in French Polynesia and which erupted in 1989, 1981, 1970, 1972 and 1983, respectively. The capital of French Polynesia, a French Overseas Collective, is Papeete, which is on the island of Tahiti. Papeete is $15,715 \mathrm{~km}$ from Paris.

However, the same active volcanic islands tend to be something of an exotic notion to the mainland population, often being a popular sun-and-beach, tropical vegetation-and-temperature or exotic food-and-rum (or wine) holiday option, with the island being a "sun-mass tourist" destination or popular cruise-ship stop over (e.g., Bardolet and Sheldon 2008; Etcheverria 2014; Garau-Vadell et al. 2014; Silvestre et al. 2008). In some cases, recognizing the island as potentially active may even be deemed unwanted due to potential damage to the same tourism (Dominey-Howes and Minos-Minopoulos 2004). Montserrat is a well-known recent example. During the 1980s Montserrat was an exotic island in the Caribbean, not well-known for its volcanic activity. However, beginning in 1995 renewed activity covered a large part of the southern half of the island, including the principle town (Plymouth), in pyroclastic deposits; necessitating evacuation (Brown 2010). Vulcano (Italy) may be argued to have suffered a similar fate during the 1888-90 eruption. Having purchased and developed the northern part of the island for sulfur-and-alum mining, as well as grape cultivation, in 1870 for $£$ 8000, the Tyneside-based (UK) entrepreneur, James Stevenson, sold-up and left having seen his beautiful villa and prosperous enterprise destroyed by air fall and ballistics, Vulcano having become 


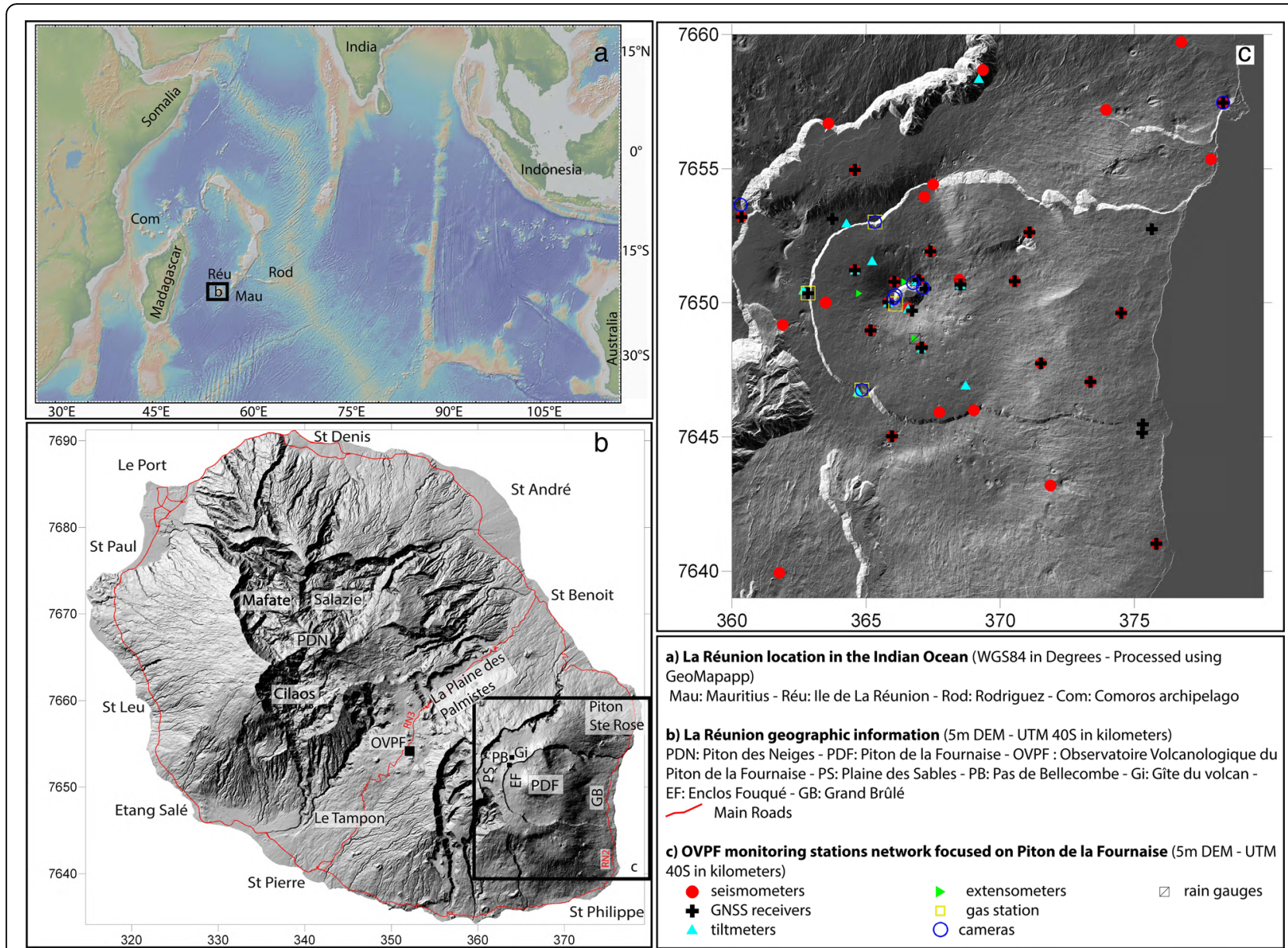

Fig. 1 Locations of $\mathbf{a}$ La Réunion island in the Indian Ocean, $\mathbf{b}$ the main towns and roads on La Réunion, and $\mathbf{c}$ the OVPF permanent monitoring network at Piton de la Fournaise. All places mentioned in the text are located in panels (b) and (c)

'an awful place' (Stevenson 2009). Thus, for the local populations of such "exotic" locations, with well-established and tight-knit local communities, the hazard, risk, impact and loss, both tangible and intangible, due to a volcanic event is very real (e.g., Payet 2007), as was witnessed during the loss of Kalapana on Kilauea (Hawaii) to lava flow inundation during the 1990s (Weisel and Stapleton 1992).

Worse, on-site observatories on active European volcanic islands are either: (i) non-existent, (ii) offshore and/or (iii) lacking in numbers and resource. Thus, during a crisis, the local staff (if there are any) may become spread so thin in collecting and interpreting data, while maintaining equipment, reporting, forecasting and situation-advisory duties, that there is no time to put out calls for help to expand the monitoring and response network. Such a beleaguered staff will need all the help that they can get; but, help needs to involve the implementation of tested and trusted techniques that provide product that is useful and that can be merged seamlessly into their response, forecasting and reporting duties (RED SEED Working Group 2016). That is, in the terminology of the remote sensing community, tools need to have been validated against reference data or 'ground-truth' (Lillesand and Kiefer 1987), so that they have gone from experimental to operational (Rudd 1974), thereby being known, trusted, valid and useable. Such help needs to be tested before, not during, a crisis (RED SEED Working Group 2016). In this case, the best way-forward is an ensemble approach whereby external (to the observatory) partners with pertinent expertise are invited to contribute to the response effort. In such a case, all partners need to integrate fully, and openly, with the group so that each partner adapts their strengths, weaknesses and roles as situations and data dictate, with all partners being open to communication and data sharing across the entire group. We here review just such a response model by focusing on a multinational and multidisciplinary group active during the five recent eruptive crises of Piton de la Fournaise (La Réunion Island, France) that occurred between 2014 and 2015; Piton de la Fournaise being the furthest active European island volcano from its mainland administration center, Paris (France). 


\section{Hazard and response setting}

In France, three main groups of volcanic overseas territories exist:

1. French Polynesia (Polynesie Française) is a "Collectivité d'Outre Mer" (COM) or an "Overseas Collective". Here the seismic network is run by CEA ("Commissariat à l'énergie atomique et aux énergies Alternatives") and real time data are locally transmitted to the "Laboratoire de Géophysique in Papeete" on Tahiti.

2. The "Terres Australes et Antarctiques Françaises" (TAAF) or the "French Southern and Antarctic Territories" includes those French overseas islands in the Indian and Antarctic Oceans, apart from La Réunion and Mayotte. The "Institut Polaire Française Paul-Émile Victor" in collaboration with the "Institut de Physique du Globe de Strasbourg" (and the Geoscope Observatory) are in charge of monitoring the Antarctic part of TAAF, which are labelled TOM (Territoires d'outre mer). The Austral part of TAAF is not permanently monitored.

3. Guadeloupe, Martinique, La Réunion and Mayotte are "Departements d'Outre Mer" (DOM). Active DOM volcanoes are monitored by "Institut de Physique du Globe de Paris" (IPGP) via a network of local volcano observatories. These are, respectively, Observatoire Volcanologique et Simologique de la Guadeloupe (OVSG), Observatoire Volcanologique et Sismologique de la Martinique (OVSM) and Observatoire Volcanologique Piton de la Fournaise (OVPF). The National Observation Service for Volcanology (SNOV) operated by the "Institut National des Sciences de l'Univers" (INSU) of the "Centre National de la Recherche Scientifique" (CNRS) is in charge of scientific duties, as well as collection and distribution of geological and geophysical data. Although Mayotte was built by volcanic activity (as was all of the Comoros Archipelago), it does not have a permanent seismic network. The most recent volcanic activity on Mayotte was 6.5 kyr BP (Zinke et al. 2001).

As part of this monitoring system, OVPF was built in 1980 in La Plaine des Cafres (15 km away from Piton de la Fournaise) to monitor volcanic activity on Piton de la Fournaise and Piton des Neiges (Fig. 1b), as well as to track seismic activity on and around La Réunion island. OVPF was set-up in the aftermath of the eccentric 1977 eruption whose lavas inundated the village of Piton Sainte Rose (Fig. 1b). Led by IPGP, whose headquarters are in Paris, OVPF has (as of December 2016) just 12 permanent staff who are based in La Plaine des Cafres (Fig. 1b). Five of these staff are scientists charged with data monitoring (checking data, derived parameters, trends, etc.), five others are engineers charged with instrument and network maintenance and monitoring. All ten have reporting duties both during eruptive and noneruptive periods (checking activity and data availability, situation updates, and reports to the head of the observatory who prepare official bulletins, etc.). Within the framework of SNOV, OVPF staff collaborate closely with IPGP staff in Paris and other French groups, or National Partners (NP), mainly at La Réunion University, at the Observatoire de Physique du Globe in ClermontFerrand (OPGC), and OPGC's academic companion department, Laboratoire Magmas et Volcans (LMV). The time difference between the OVPF and French sites is 2 or $3 \mathrm{~h}$ depending on the season, where Paris and Clermont Ferrand is UTC +1 and La Plaine des Cafres is UTC + 4. Specific agreements between OVPF and other international agencies, or International partners (INP), such as the Hawaiian Volcano Observatory (USGS-HVO, Hawaii, USA), Istituto Nazionale di Geofisica e Vulcanologia (INGV - Pisa, Palermo and Catania, Italy) and Chalmers University of Technology (Gothenberg, Sweden), as well as informal arrangements with INPs such as Università di Torino (Turin, Italy), have also permitted data sharing, technology upgrade and knowledge transfer beyond the national framework. Here we note that, informal agreements based exclusively on mutual and collaborative efforts, as carried out here with Università di Torino, are developed during an eruptive crisis. However, as discussed later, continuity of service provision, data validation efforts, transparency and efficiency then benefit from development of more robust, formal agreements developed during non-eruptive periods.

During and between crises the role of OVPF is to communicate with the national, regional and local responding agencies. Following the French national plan for response protocols during a crisis at Piton de la Fournaise, the call-down procedure is laid out in "Organisation de la Réponse de SEcurité Civile" (ORSEC), i.e., the "ORSEC-Piton de la Fournaise" plan. Within this plan OVPF communicates only with the prefecture via the "Etat Major de Zone et de Protection Civile de Ocean Indien" (EMZPCOI). The prefecture (decentralized administrative service of the French state) then communicates with other actors in the response chain. For each eruption, and for any change in volcanic activity, a Volcano Observatory Notice for Aviation (VONA) is also sent to the Volcanic Ash Advisory Center (VAAC) in Toulouse (France). OVPF reporting duties also include communication with the air quality office in Saint Denis (La Réunion). The period between 2014 and 2015 was particularly challenging because five eruptions occurred in short succession, with one during June 2014, and then four during 2015 (in February, May, July-August and August-October), the last of which 
ranked as the fifth largest eruption since records began in 1700 (Michon et al. 2015; Peltier et al. 2016). During these events round the clock service was maintained by OVPF. During non-eruptive periods, when the observatory is not staffed out of working hours, full $24 \mathrm{~h}$ service (during all days of the year) is maintained by instrumental monitoring and an alarm, which triggers in the case of a change in seismic activity, where the alert is sent to a scientist-on-duty. Duties at the observatory between eruptions thus continue on a 24/7 basis, and include daily checking of activity and proper functioning of all networks, plus creation of daily reports.

\section{OVPF monitoring network}

On site, OVPF-IPGP maintains four types of groundbased real-time monitoring networks, namely (in order of network size): (i) seismic, (ii) geodetic (deformation), (iii) geochemical (gases), and (iv) imagery, including permanently installed visible and infrared cameras (Fig. 1c). The OVPF team is also charged with performing detailed syn-eruptive sampling and mapping of eruptive products (Additional file 1). At the national level, OPGC and LMV are charged with satellite remote sensing $\left(\mathrm{OI}^{2}\right.$ : "Observatoire InSAR de l'Océan Indien", https://wwwobs. univ-bpclermont.fr/SO/televolc/volinsar/; HotVolc: HotVolc Observing System, https://wwwobs.univ-bpclermont. $\mathrm{fr} / \mathrm{SO} /$ televolc/hotvolc/), plus petrochemical and volcanological analysis of the eruptive products (Dynvolc: Dynamics of Volcanoes, http://wwwobs.univ-bpclermont.fr/SO/ televolc/dynvolc/; GazVolc: Observation des gaz volcaniques, http://wwwobs.univ-bpclermont.fr/SO/televolc/gaz volc/).

International collaboration with the INGV in Pisa and the Università di Torino also allows near-real time provision of potential lava flow paths and validated timeaveraged lava discharge rate (TADR), respectively. These products have been coupled with operational lava flow modelling at LMV to allow assessment of potential lava flow run-out. Collaboration with Chalmers University (Gothenburg, Sweden) is fundamental for post-processing and validation of $\mathrm{SO}_{2}$ flux data acquired by the permanent NOVAC DOAS network. The Network for Observation of Volcanic and Atmospheric Change (NOVAC) is a system of automatic gas emission monitoring at active volcanoes using a worldwide array of permanently-installed differential optical absorption spectroscopy (DOAS) scanners which measure volcanic gas emissions by UV absorption spectroscopy (Galle et al. 2010). We focus, here, on how these disparate external groups integrated to provide timely and useful product during effusive crises involving emplacement of lava flow fields that threatened infrastructure (mostly the island belt road) between 2014 and 2015 . A flowchart synthesizing the information chain, plus the dependence of actions and data between the observatory, is given in Fig. 2.

\section{La Réunion: Volcanic hazard, risk and perception}

The relatively late creation of a continuous monitoring system, where the observatory was established in 1979, together with the recent age of permanent human settlement on the island, where the first people arrived from Brittany (France) in the seventeenth century (Vaxelaire 2012a), have meant that the observatory and the population have had to deal with a growing awareness of the variability, in time and space, of the eruptive behavior of Piton de la Fournaise (see Morandi et al. 2016 for review). Since the creation of the observatory, 66 eruptions (1981-2016) have occurred with durations of between 0.3 and 196 days emitting, on average, a bulk volume of $9 \times 10^{6} \mathrm{~m}^{3}$ (Peltier et al. 2009; Roult et al. 2012). With the exception of the 1986 and 1998 eruptions, all lava emissions have been confined inside the uninhabited 'Enclos Fouqué' caldera (Fig. 1b), and have involved vents opening inside the summit craters or on the flanks of the central cone, or further away to the east on the floor of the Enclos Fouque caldera. Eight of these eruptions (March 1986, March 1998, June 2001, January 2002, November 2002, August-October 2004, February 2005, and April 2007) have cut the island belt road - the only link between the southern and northern part of the island on the eastern flank (RN2, Fig. 1b). Large-volume eruptions have been documented, with that of April 2007 (Staudacher et al. 2009), being of quite shortduration (less than 1 month). Effusive events can also be long-lasting (several years), where decade-long phases of continuous activity, punctuated by short-lived explosive events, have been observed in the geological record (Peltier et al. 2012; Michon et al. 2013). In 2007, the most voluminous eruption of historical times occurred at an altitude of $570 \mathrm{~m}$ above sea level, $400 \mathrm{~m}$ north of the southern wall of the Enclos Fouque caldera. The eruption buried $1.5 \mathrm{~km}$ of the belt road under $60 \mathrm{~m}$ of lava, caused gas exposure problems in towns on the east and west coasts, and prompted the evacuation of the nearby village of Le Tremblet. Likewise the eruptions of 1986 and 2002 also required evacuation of villages north or south of the Enclos Fouqué caldera.

There are around 840,000 habitants on La Réunion island, and over 245,000 permanent residents on the volcano flanks. Tourism is a major industry, accounting (in 2014) for $7.8 \%$ of the Gross Domestic Product, 8500 jobs (3.2\% of total employment), $40.7 \%$ of total exports and $3.1 \%$ of total investment (WTTC 2015), where the warm waters, exotic marine life, white-sand beaches, surfing and tropical coastline are big draws (e.g., The Lonely Planet 2015; Michelin Green Guide 2015). However, tourism has been affected by two water-related hazards, 


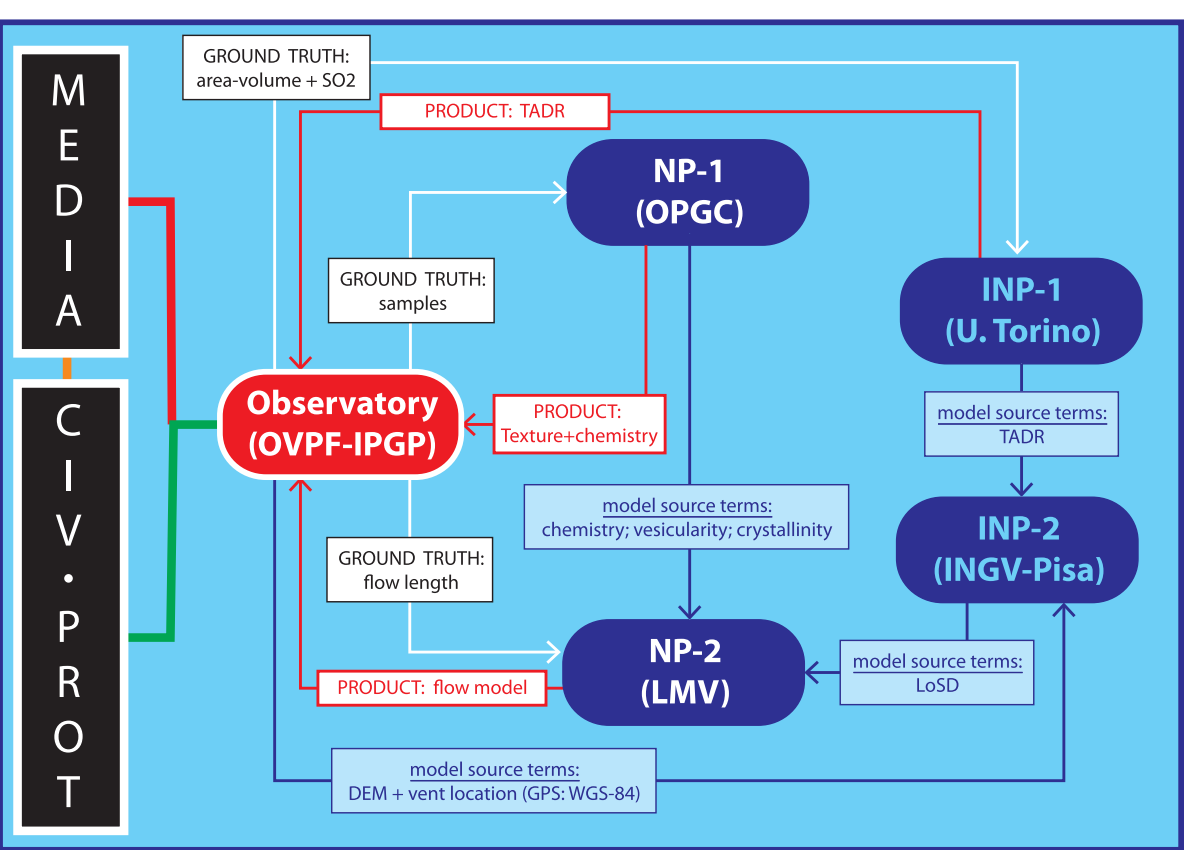

Fig. 2 Communication route into OVPF through, and between, national partners (NP) and International partners (INP) during the on-island effusive crises of 2014-2015. Ground truth flow out (via white arrows) of the observatory, model source terms are passed (via blue arrows) between the partners, and products are passed back (via red arrows) to the observatory. These are folded into one-voice communication onwards to civil protection (green line), and only on to the media through carefully controlled routes (orange and red lines). The national partners were OPGC (NP-1), for textural and geochemical products and LMV (NP-2) for lava flow simulations; and the International Partners were the Università di Torino (INP-1) for satellite-based TADR provision and INGV-Pisa (INP-2) for lava flow modelling, with there being open, two-way communication routes between all partners

the "shark crisis", where there have been 42 attacks since 1990, and Chikungunya epidemics, both of which have been widely disseminated by global media (e.g., Santora 2015, Stewart 2015, Surfer Today 2016). Chikungunya is a mosquito-borne virus characterized by arthralgia or arthritis, where an outbreak between March 2005 and April 2006 resulted in 255,000 cases (i.e., it affected 30\% of the population), was responsible for $87 \%$ of the deaths on the island during the same period (Josseran et al. 2006), and was followed by a sharp down turn in visitor numbers (INSEE 2016). As a result, the tourism strategy has turned to the attractiveness of the terrestrial environment. This includes the draw of an active volcano (Gaudru 2010), which is classed as a World Heritage Site by UNESCO. This policy re-orientation has allowed La Réunion to maintain visitor numbers at a level of around 420,000 per year since 2007 , this being the same as the pre-2006 level; where numbers dipped to 300,000 in 2006 following the Chikungunya epidemic (INSEE 2016). Although the tourist office and local media promotes Piton de la Fournaise and its activity as a tourist attraction, portraying the volcano as dangerous or hazardous would have a negative effect on tourism. In terms of the resident population, a recent survey of Réunion's resident population on volcanic risk perception thus revealed a relatively poor knowledge of the volcano and its activity; although, the same people had a high level of trust in scientists to provide accurate and reliable information (Nave et al. 2016).

\section{The tourist draw and hazard to tourists}

An on-going eruption is a positive draw to the Parc national de La Réunion, which covers 105,000 ha (or $42 \%$ of La Réunion island), and the access town (for Piton de la Fournaise) of La Plaine des Cafres and the visitors center (La Cité du Volcan) dedicated to the volcano and its activity. The first tourist activity at Piton de la Fournaise was in the form of scientific expeditions during the nineteenth century. These expeditions were usually composed of a foreign naturalist on a visit to the island, some local volcano experts, guides, porters, and governors or other senior administrative officials. At that time, a guide was quite rare and difficult to find on the island and the porters, initially slaves, were often frightened at the idea of going to the "territory of the devil". In 1863, for example, Baron Carl Claus Von Der Decken (Kersten 1871; Kersten et al. 2016) spent 6 days exploring the volcano, departing from Saint Denis and pausing to find a guide at La Plaine des Palmistes. Such expeditions were increasingly facilitated by the opening of a railway, which was constructed along the coast from Saint Denis to Saint Pierre and Saint Benoît, in 1882 (Vaxelaire 2012b). 
In 1925 a first Gite was built on the site of the present one near Pas de Bellecombe (Fig. 1b), and in 1933 construction of Madame Brunel's Hotel at La Plaine des Cafres (near the current OVPF buildings - Fig. 1b) gave explorers a base camp. In 1957, the Office National des Forêts (National Forestry Office) initiated the construction of the "Route du Volcan", which was completed as far as Pas de Bellecombe in 1968.

Germanaz $(2005 ; 2013)$ estimated the number of visitors to Piton de la Fournaise between 1750 and 1965 as being less than a thousand per year. Between 2011 and 2016, The Office National des Forêts estimated that around 350,000 people per year used the Route du Volcan, with one-in-three visitors hiking down into the Enclos Fouqué caldera. In June 1972, a protocol was put in place whereby policemen prohibited access to Pas de Bellecombe during an eruption. In November 2002, to limit unauthorized access to the Enclos Fouqué cadera during periods of closure, a gate was installed in Pas de Bellecombe. This gate is a physical means of limiting access to the volcano by blocking the narrow entrance to the only path down the 130-160 m high cliffs of the caldera wall (Fig. 3a). However, the position of lock-down by the local civil protection is contrary to certain political, economic and even public wishes to use the volcano as tourist draw for La Réunion. Strategies to communicate the beauty of the volcano and its eruptions are widespread ranging from numerous glossy brochures in hotel lobbies and adverts in the local newspapers published by tour operators, guides, adventure companies, and air tours, to press releases to international media and work plans for rangers accompanying hikers during eruptions. The publicity campaign intensifies during periods of eruptive crisis, and includes provision of space on shuttle buses operating between La Plaine des Cafres or Le Tampon and Pas de Bellecombe.

On a normal day 2000-3000 people use the main visitor access point for the Dolomieu crater (Bello 2010), this being Pas de Bellecombe (Fig. 1b). This load increases enormously during activity (Fig. 3b, c). Given a traffic density of 270 cars per kilometer at peak flow (estimated from Fig. $3 \mathrm{~b}$ on the basis of nose-to-tail traffic in both directions at peak flow), this gives 1160 cars parked on the final $4 \mathrm{~km}$ of the road to Pas de Bellecombe. If we add the capacity of the Pas de Bellecombe car park (1200 cars), then this amounts to around 2400 cars. Given an average number of four people per car, this is a visitor load on Pas de Bellecombe during the night of 31 July - 1 August 2015 of almost 10,000. We round up because this does not take into account emergency parking opened at La Plaine des Sables, as well as the car park at, and $1.3 \mathrm{~km}$ road, to the Gite du Volcan (Fig. 1b), a restaurant/lodge $900 \mathrm{~m}$ north of Pas de Bellecombe into which around 100 stranded tourists broke-in, so as to shelter for the same (cold) night. However, this increase in traffic overwhelms parking and access facilities, causing severe congestion in towns lying along access roads to the Enclos Fouque caldera and Dolomieu crater, including the towns of Saint Philippe and Sainte Rose on the RN2 (Bello 2010). A high tourist load can also be damaging to the flora of the park itself (Bello 2010), and will (i) be associated with an increased number of accidents and illness among park visitors (Heggie and Heggie 2004; Heggie 2005), (ii) result in increased need for emergency search and rescue operations (Heggie 2008; Heggie and Heggie 2008; 2009), and (iii) cause fatalities if tourists stray into dangerous environments (e.g. Heggie 2009) or unstable areas subject to collapse (e.g. Perkins 2006). Following the 31 July - 2 August 2015 eruption, the local newspaper reported 41 hikers evacuated from closed zones, 14 victims of minor injuries and illnesses, and 11 cases of hypothermia at Pas de Bellecombe, plus four cases of illness, some minor injuries and cases of fatigue on the road between La Plaine des Cafres and Pas de Bellecombe (L.R. 2015). The eruption was just $50 \mathrm{~h}$ in duration.

\section{Methodology: Near-real time tools and integration}

Our focus here is on running and delivering, in as timely-a-fashion as possible, lava flow simulations during an effusive crisis to assess and update likely inundation zones. We here use the merged output from two lava flow models: FLOWGO and DOWNFLOW, the FLOWGO model already having been initialized and validated for channel-fed flow at Piton de la Fournaise (Harris et al. 2015). Merged application of FLOWGO-DOWNFLOW has also been tested for near-real time lava flow simulation using a feed of lava time-averaged discharge rate (TADR) derived from $1 \mathrm{~km}$ spatial resolution thermal data from satellite-based sensors such as MODIS (Wright et al. 2008).

Any lava flow simulation model first requires initialization with vent location, which is provided by OVPF as part of their monitoring and response procedures. The key source term then becomes TADR, which can potentially be obtained in near-real time, and multiple times per day, from satellite-based sensors imaging in the thermal infrared. The Spinning Enhanced Visible and Infrared Imager (SEVIRI) sensor on the MeteoSsat Second Generation (MSG) satellite series provides thermal infrared data for Piton de la Fournaise at a spatial resolution of $3 \mathrm{~km}$ and nominal temporal resolution of 15 min (Gouhier et al. 2016). These data are potentially capable of providing TADR in a timely fashion. However, tests on GOES data have shown that, although variations in volcanic radiance can be trusted to provide arrival time of magma at the surface with a precision of $7 \pm 7.5 \mathrm{~min}$ (Harris et al. 1997a) and to track variations in effusive activity at $15 \mathrm{~min}$ time steps (e.g., Mouginis-Mark et al. 

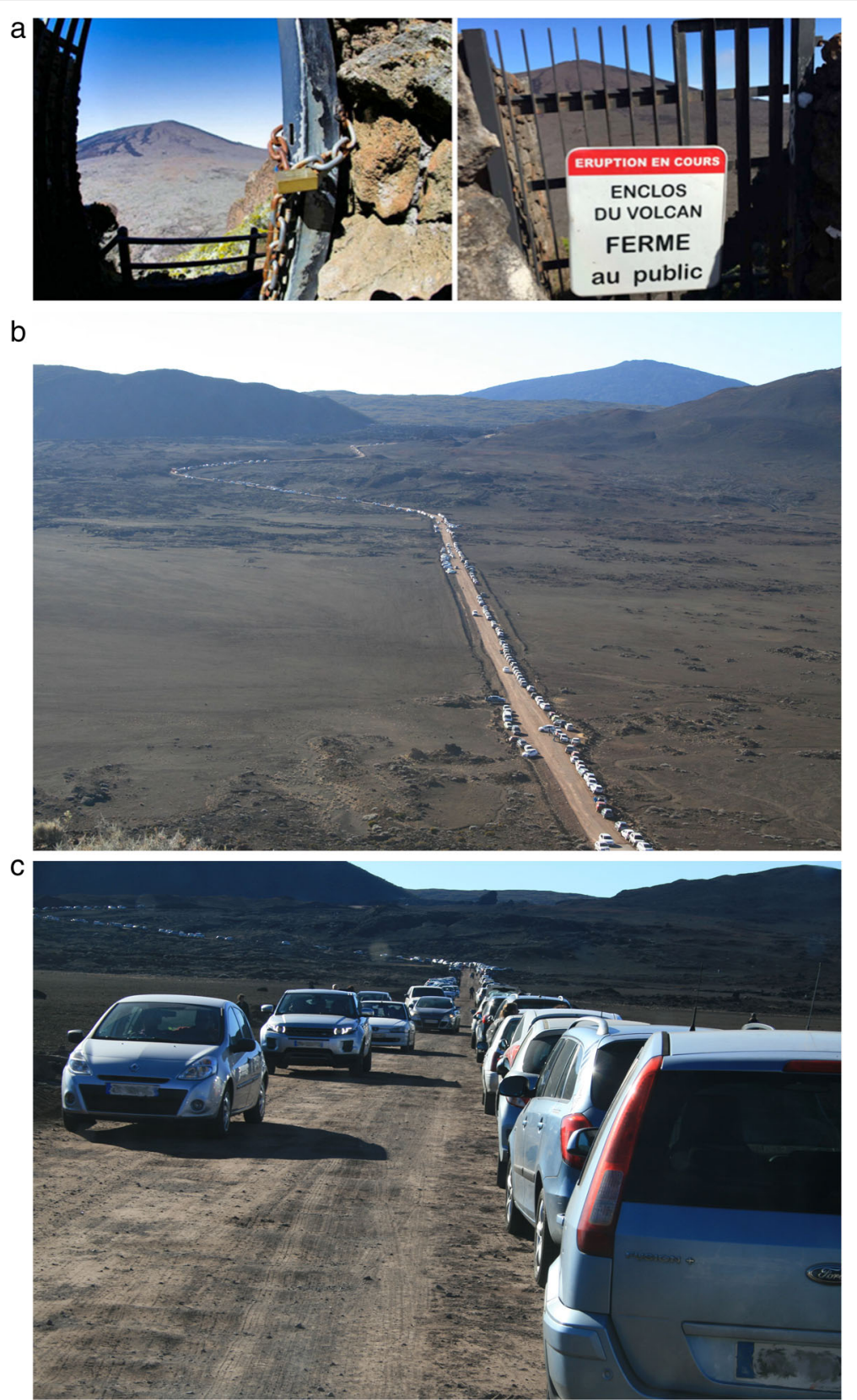

Fig. 3 a The gate at the head of the trail down into the caldera at the Pas de Bellecombe entry point between and during effusive crises. b;c Congestion on the Route du Volcan at the Plaine des Sables around 06:40 (local time) on 1 August 2015: the second day of the July-August 2015 eruption. After these photos were taken, parking next to the road was banned and cars were allowed to ascend from La Plaines des Cafres in groups of 100, as space became available in designated parking areas. A mini-bus shuttle service was also added from bases in La Plaines des Cafres and Tampon. This caused severe traffic and parking congestion, but no doubt a short economic boom, for the town of La Plaines des Cafres

2000), TADR derived from 4-km pixel data were not reliable (Dawn Pirie, Hawaii Institute of Geophysics and Planetology, unpublished data, 1999). TADR were not, thus, included as part of "hot spot" products delivered to recipient observatories by the Hawaii Institute of Geophysics and Planetology (HIGP, University of Hawaii, Honolulu, USA) because they were not deemed valid or trustworthy (Harris et al. 2001). This is a result of the large pixel size and mixed pixel problems, as well as pixel deformation, where pixels become increasingly large, ovoid, overlapping and rotated with scan angle (Harris 2013). Worse at high scan angles, or with extreme Earth curvature (which is the case for SEVIRI observations of Piton de la Fournaise), unreliable spectral radiances have been recorded (Holben and Fraser 1984; Singh 1988; Coppola et al. 2010), so that spurious data at high scan angles tend 
to be filtered out of quantitative analyses (e.g., Tucker et al. 1984; Goward et al. 1991; Harris et al. 1997b). Following Frulla et al. (1995), radiances for volcanic hot spots are deemed unreliable at scan angles of greater than $50^{\circ}$, where SEVIRI views Piton de la Fournaise at an angle of $63.4^{\circ}$. At such high scan angles, while over-estimates of spectral radiance, and hence TADR, will result from smearing of the anomaly due to extreme pixel overlap effects and point-spread-function problems (e.g., Markham 1985; Breaker 1990; Schowengerdt 2007), underestimates will result from atmospheric effects (Coppola et al. 2010) and topographic shadowing of all or part of the thermal anomaly (Dehn et al. 2002). Even local topographic features, such as cones, levees and skylights have been shown to play a role in shadowing the anomaly at high scan angles (Mouginis-Mark et al. 1994), causing detection problems even at quite low scan angles for active lava surrounded by topographic highs (e.g., Wooster et al. 1998; Harris et al. 1999; Calder et al. 2004).

We see this problem in Fig. 4. TADR derived from the 1-km MODIS data following the method of Coppola et al. (2013) are in agreement with those obtained from areal photography and gas flux data. However, those obtained from 3-km SEVIRI data are consistently much lower, and show a large degree of scatter. Much of this scatter is due to the fact that the SEVIRI data have not been cleaned for cloud contamination. All the same, the trend apparent in the SEVIRI data does not match that of the MODIS-photogrammetry-gas data. This is likely due to changing shadowing effects (due to growth and decay of cone rims, levees, etc.) and the evolving form of the lava flow field in relation to its location in the detected pixels. This latter affect will continually modify the influence of the point-spread-function which, as noted above, will be exaggerated at high scan angles. We thus prefer to use $1-\mathrm{km}$ spatial resolution, acquired at low scan angles from polar orbits, for TADR-derivation. Such data are nominally available four times per day, a frequency sufficient to describe an effusive event evolving over the time scale of hours (e.g., Wooster and Rothery 1997; Harris et al. 2000b; Wright 2016). Better, TADR derived from such data have been validated for Piton de la Fournaise by Coppola et al. (2009; 2010), and appear valid from the ground-truth test completed in Fig. 4.

Other source terms involve chemical and petrological data, to set and check rheological models used, as well as physical volcanological measurements (at-vent temperature, crystallinity and vesicularity). These data can, in turn, also be used to track the effusive event (Coppola et al. 2017). Finally, data processed post-event can then be used for debriefing purposes and supplementary validation checks. While we use lava unit area and length derived from observations, photogrammetric surveys and InSAR data (Bato et al. 2016) for checking model-derived lava flow run-outs, $\mathrm{SO}_{2}$ and thermal camera data are used to check the validity of TADR obtained from MODIS data. We here review the methodologies (as well as their application in near-real time, problems and delivery delays) that formed this chain from source term provision, through model execution to output validation during the five effusive eruptions that

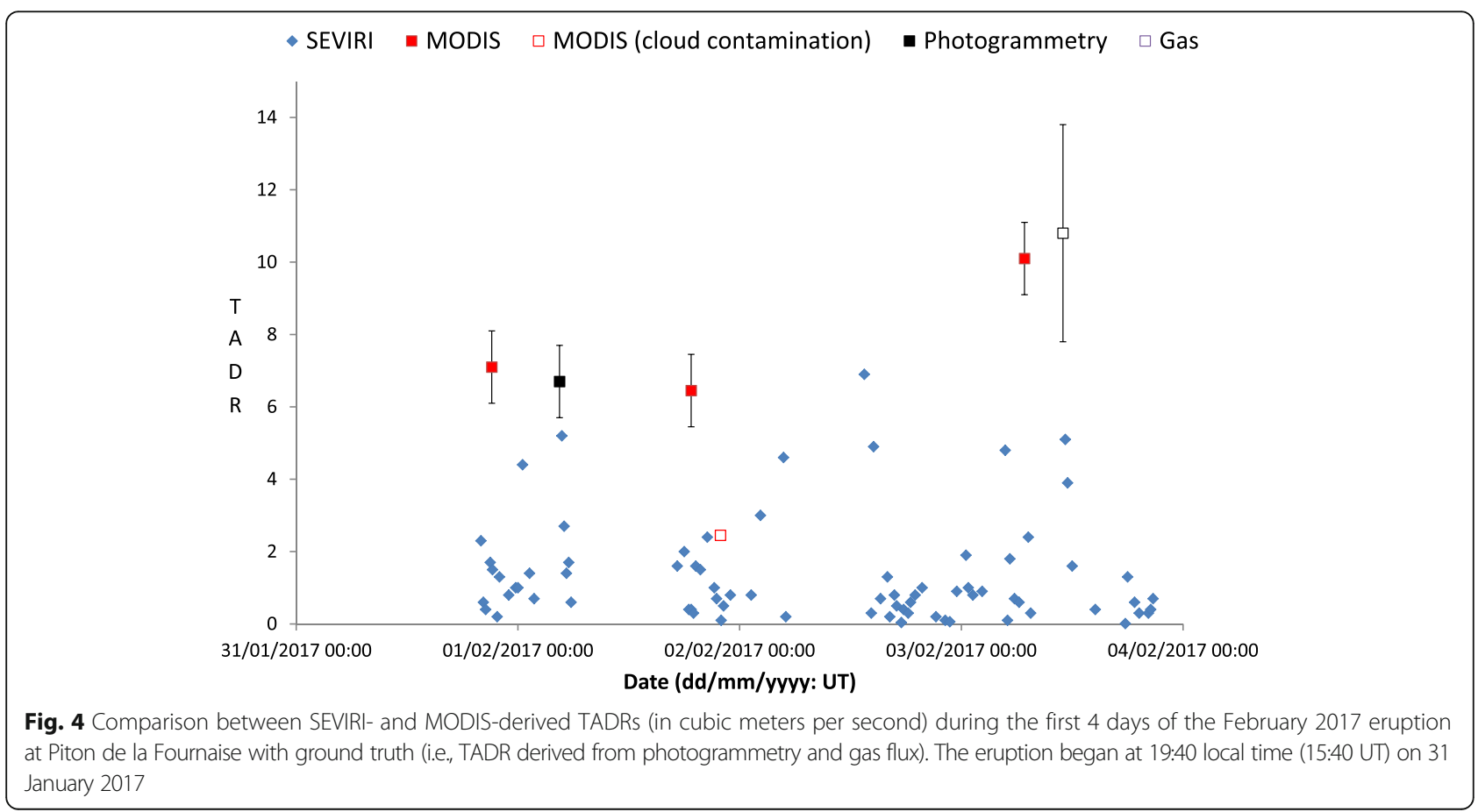


comprised the 2015-2016 cycle of activity (Peltier et al. 2016; Coppola et al. 2017) at Piton de la Fournaise.

\section{OVPF response}

At the onset of an eruption, dyke location plus propagation direction and velocity is tracked on monitors in the OVPF operations room, in real-time, using the live data stream from the permanent seismic and geodetic networks. Upon eruption, vent location, eruptive fissure length and geometry, plus the number and activity of eruptive sources, are assessed using the OVPF permanent camera network, whose images are also streamed live to the operations room, and field reconnaissance. Remote surveillance is followed by in-situ inspection and/or civil protection helicopter-based over-flight including one OVPF agent. In-situ GPS-location of effusive vents, sampling of eruptive products (solids and gases), and infrared and visible image surveys are typically performed during the first few hours of an eruptive event, when weather conditions are favorable. Additional file 1 provides an overview of the frequency of: (i) sampling of solid products (pyroclasts, lavas, sublimates), (ii) in situ analyses of gas composition and fluxes, and (iii) thermal and visible camera surveys during the 20142015 events. A representative set of solid samples is then sent during, and/or immediately after, each eruptive event to LMV and IPGP for textural, chemical and petrological analyses.

Lava flow volume estimates are currently based on field mapping, photogrammetry and InSAR analysis (Peltier et al. 2016). Precise volume estimations are generally performed post-event or late during a long-lasting event due to (i) the cost of, and preparation time required for, satellite and/or aerial photography acquisitions, (ii) the need for Ground Control Point (GCP) measurement, and (iii) the complexities of data processing. However, due to new research funding from the Agence National de Recherche (ANR), a new satellite image-purchase program (Kalidéos 2 by CNES) and implementation of crowd sourcing techniques, volume estimation and lava flow mapping are becoming increasingly available during eruptive events and with low degrees of latency. Crowd sourcing involves use of high definition drone-derived images available on YouTube, collaboration with a network of professional photographers and journalists, and networking with drone pilots who all provide OVPF with images for photogrammetry free of charge.

\section{TADR derivation using MIROVA}

MIROVA (Middle InfaRed Observation of Volcanic Activity) is an automated global hot spot detection system run at the Università di Torino (Coppola et al. 2016). The system is based on near-real time processing of MODerate resolution Imaging Spectroradiometer (MODIS) data to produce hot spot detection, location and tracking products (Fig. 5). MODIS is a multispectral radiometer carried aboard the Terra (EOS-AM) and Aqua (EOS-PM) polar orbiting satellites. MODIS acquires data of the entire Earth's surface in 36 wavebands and offers a temporal coverage of $\sim 4$ images per day at a spatial resolution of $1 \mathrm{~km}$ in the infrared (IR) bands, specifically bands 21 and $22(3.929-3.989 \mu \mathrm{m}$, low and high gain, respectively), $31(10.78-11.28 \mu \mathrm{m})$ and 32 (11.77$12.27 \mu \mathrm{m})$. Using MODIS, MIROVA completes automatic detection and location of high-temperature thermal anomalies, and provides a quantification of the volcanic radiant power (VRP), within 1 to $4 \mathrm{~h}$ of each satellite overpass (Coppola et al. 2016). With each overpass, thermal maps (in .kmz format for use with Google Earth) and VRP time-series are updated on the MIROVA website (www.mirovaweb.it). This provides the user with immediate access to the post-processed products, allowing visual inspection of the images so that data contaminated by clouds and volcanic plumes, or acquired at poor viewing geometries (i.e high satellite zenith angles), to be discarded (Coppola et al. 2013).

Satellite-based thermal data have been used operationally to estimate the lava discharge rates during effusive eruptions since first application in 1997 (Harris et al. 1997a). This approach relies on the observed relationship between lava discharge rate, lava flow area and thermal flux (e.g. Pieri and Baloga 1986; Wright et al. 2001; Harris and Baloga 2009, Garel et al. 2012). For any given eruptive condition, this relationship allows VRP to be set as proportional to the time-averaged lava discharge rate (TADR) using the coefficient of proportionality, $\mathrm{c}_{\mathrm{rad}}=$ TADR/VRP (Coppola et al. 2013). Validation by Coppola et al. $(2009 ; 2010 ; 2013)$ indicates that the eruptions of Piton de la Fournaise are characterized by a best-fit coefficient of between $1.4 \times 10^{8}$ and $2.9 \times 10^{8} \mathrm{~J}$ $\mathrm{m}^{-3}$. This range likely reflects variation in eruptive conditions, such as different emplacement styles (i.e., channel- versus tube-fed) or underlying topography (steep versus gentle slopes). Comparison with post-event lava flow volumes indicated that short-lived ( $<15$ days), lowvolume $\left(<3 \times 10^{6} \mathrm{~m}^{3}\right)$ eruptions are best described by the upper bound of the coefficient range (Coppola et al. 2017), with the lower bounds being more applicable to eruptions lasting more than 2 weeks and emitting more than $5 \times 10^{6} \mathrm{~m}^{3}$ of lava. However, in the absence of synevent validation, upper, median and lower bounds on MIROVA-derived TADR are given to take into account this uncertainty (Fig. 5). During the opening phases of each eruption (i.e., during the first $48 \mathrm{~h}$ ), as well as during periods of major changes in output, TADR timeseries were updated at-least four times per day and were delivered, via email, to OVPF for ingestion into the on- 

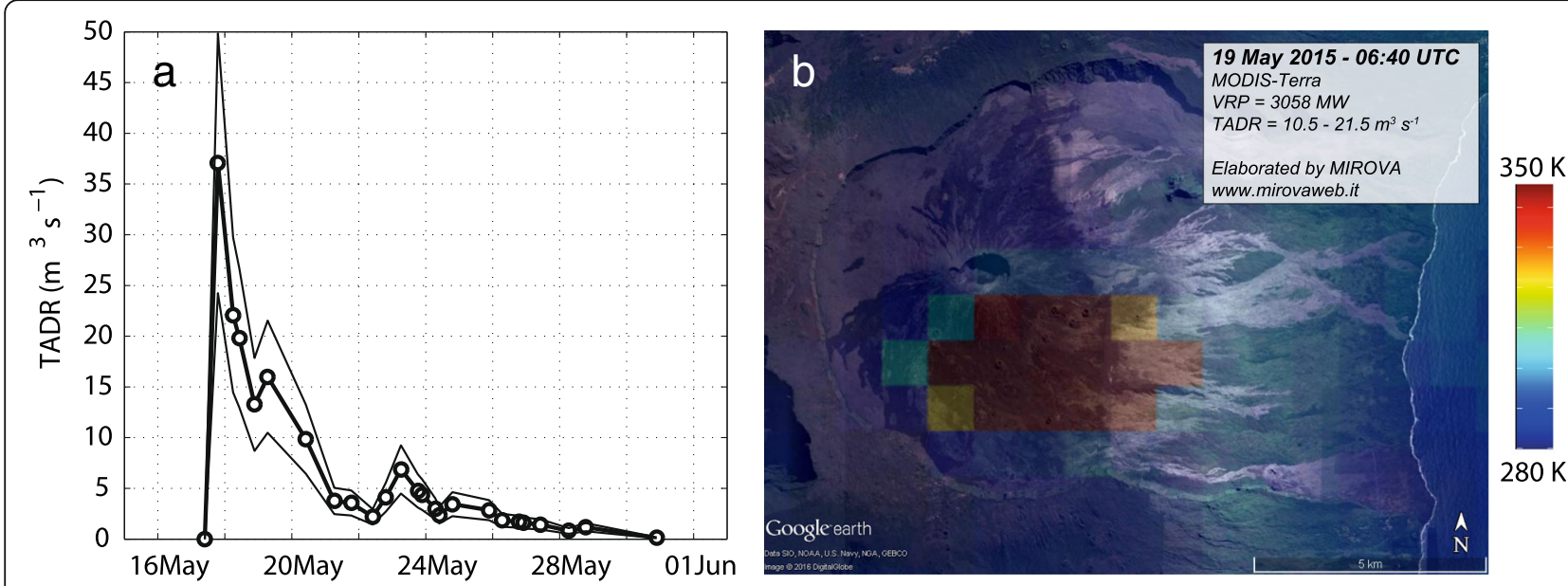

Fig. 5 a MIROVA-derived TADRs (circles) recorded during the May 2015 eruption. Uncertainty related to variable emplacement styles or underlying topography is taken into account by the upper and lower bounds of each TADR estimate (thin solid lines). $\mathbf{b}$ Example of thermal image (Brightness Temperature at 3.9 m: MODIS band 22) output by the MIROVA system and overlain (in transparency) on Google Earth to allow rapid geolocation of thermally anomalous pixels

going hazard assessment and response. They were also sent to INGV-PI and LMV for initialization and updating of model-based lava flow run-out assessments. This service was maintained during the June 2014, May 2015, July-August 2015 and August-October 2015 eruptions.

\section{Initialization and execution of DOWNFLOW and FLOWGO}

DOWNFLOW is a stochastic model developed at INGV-Pisa that searches for the most likely array of down-hill paths that a lava flow will follow on a DEM of a given spatial resolution, vertical resolution and error (Favalli et al. 2005). During each eruption, DOWNFLOW was initialized upon reception of the new vent location using the 25-m resolution DEM of Piton de la Fournaise based on the 1997 topography. For each eruption DOWNFLOW was run twice. Each run involved 10,000 iterations but with the random elevation change introduced at each iteration $(\Delta \mathrm{h})$ first set at $0.8 \mathrm{~m}$, and then at $2.5 \mathrm{~m}$. Based on calibration against the 1998, 2000, 2004 and 2005 lava flows, $\Delta \mathrm{h}=2.5 \mathrm{~m}$ gives the best fit for DOWNFLOW in regions proximal to the vent, but $\Delta \mathrm{h}=0.8 \mathrm{~m}$ provides the best fit in the distal regions. Each run took less than $1 \mathrm{~min}$ to execute. Upon run completion, a text file containing the slope down the line of steepest descent and a map showing all flow paths projected onto the shaded relief of Enclos Fouqué were sent via email attachment to LMV and OVPF. The slope file integrated values over $10 \mathrm{~m}$ steps so as to be compatible with ingestion into FLOWGO, whose distance increment is $10 \mathrm{~m}$ (Harris and Rowland 2001). Results of the DOWNFLOW runs for the May 2015 eruption are given in Fig. 6.

FLOWGO is a thermo-rheological model designed to assess the one-dimensional thermal, rheological and dynamic evolution of lava flowing down a channel (Harris and Rowland 2001). Although not intended to give flow length, the point at which lava reaches its freezing point in the model channel is usually close to the actual lava flow run-out distance, if flow is cooling-limited (Harris and Rowland 2001). FLOWGO was initialized for Piton de la Fournaise using geochemical and textural data from the 2010 eruption (Harris et al. 2016) as well as the temperature-dependent viscosity model derived for Piton de la Fournaise by Villeneuve et al. (2008). Initially, FLOWGO was run each time TADR was updated by MIROVA. However, it was found to be more efficient to simply run FLOWGO at a range of TADRs to provide a run-out look-up table, which was updated if TADR rose above, or fell below, the look-up table range. Look-up tables were sent in both graphical form (Fig. 7) and as a two-column text file (giving TADR and run-out) to OVPF by email.

\section{Delivery delays}

Lava flow model product and TADR were delivered to OVPF with a delay of up to $24 \mathrm{~h}$. For a lava flow front advancing at a few tens of meters per hour, and several kilometers distance from vulnerable infrastructure, then a $24 \mathrm{~h}$ delay may be reasonable. But for faster moving flows, closer to vulnerable sites, this may need to be reduced; and delivery delay can be reduced to an hour or so.

The May 2015 eruption began at 12:45 LT (8:45 UT) on 17 May and two OVPF staff members arrived, by helicopter, at the new eruptive fissure around $3 \mathrm{~h}$ later at 15:30 LT (11:30 UT). At 18:30 LT (14:30 UT), the two observers decided to stay near the eruptive fissure to make IR camera acquisitions during the night returning on foot and then car to OVPF later in the evening, thus sending the vent coordinate to LMV after closure of the 


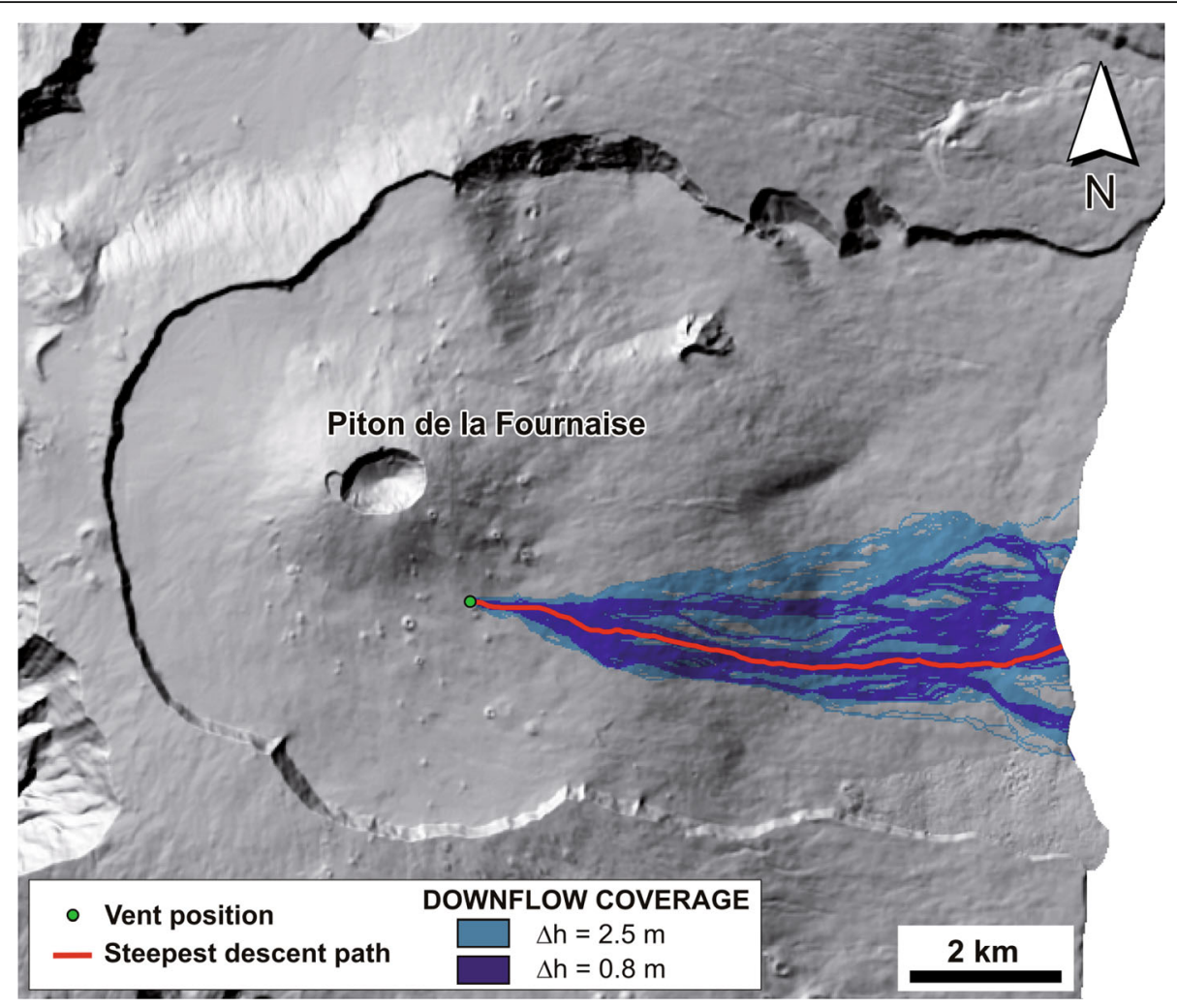

Fig. 6 Lava flow paths forecast by DOWNFLOW for the May 2015 eruption for noise levels $(\Delta \mathrm{h})$ of $0.8 \mathrm{~m}$ and $2.5 \mathrm{~m}$ on the shaded relief of the same DEM used to run DOWNFLOW. The slope taken down the steepest descent path was that sent to LMV for initialization of FLOWGO

mainland offices (after 21:00 LT; 17:00 UT). All the same, the vent coordinate was sent from LMV to INGV at 22:39 LT (18:39 UT). DOWNFLOW and FLOWGO runs were then executed during the following $4 \mathrm{~h}$, with product being delivered to OVPF at 02:17 LT on 18 May (22:17 UT, 17 May); thus being picked up by the OVPF director early the following morning. In this case, if OVPF could have returned the position of the main vent to LMV at the point of first observation, then the first simulation could have been delivered to OVPF in less than $5 \mathrm{~h}$. Indeed in some cases we were able to reduce the delay between announcement of eruption onset and delivery of vent location coordinates, to provision of DOWNFLOW maps and FLOWGO look-up tables, to about $1 \mathrm{~h}$. However, it is currently difficult to guarantee a turn-around of less than $5 \mathrm{~h}$ for three reasons:

- TADR used for initialization of FLOWGO needs to wait for the first cloud-free MODIS overpass. In the best case, this wait-time was just $23 \mathrm{~min}$, but was typically 3-to-4 $\mathrm{h}$.

- Due to the lack of GSM (Global System for Mobile Communications) coverage over a large part of the volcano, the ability to communicate between on-site observers and the observatory is extremely limited, and messages need -literally - to be carried back by hand resulting in delivery delays for vent location if observers are out of range.

- The management priorities at OVPF, where a very small team needs to deal with all scientific, media and civil defense reporting duties, mean that it may take some time to communicate vent coordinates, especially at the beginning of an eruption. For example, at the beginning of the July 2015 eruption, the director took calls from at-least seven journalists during the first $2 \mathrm{~h}$ of activity, while also having to organize field crews and meet civil protection call down duties. Remaining staff were spread thin keeping up with real-time geophysical and field-based surveillance duties and reporting.

However, the resulting delay in product delivery of typically $3-4 \mathrm{~h}$ was acceptable for the cases tracked here, where lava flows had their sources high on the volcano flanks, at-least $5 \mathrm{~km}$ from vulnerable infrastructure.

\section{Real time lava flux estimation based on $\mathrm{SO}_{2}$ flux measurements}

At the eruptive vent, lava effusion rate is proportional to the gas flux, provided that volatiles are dominantly 


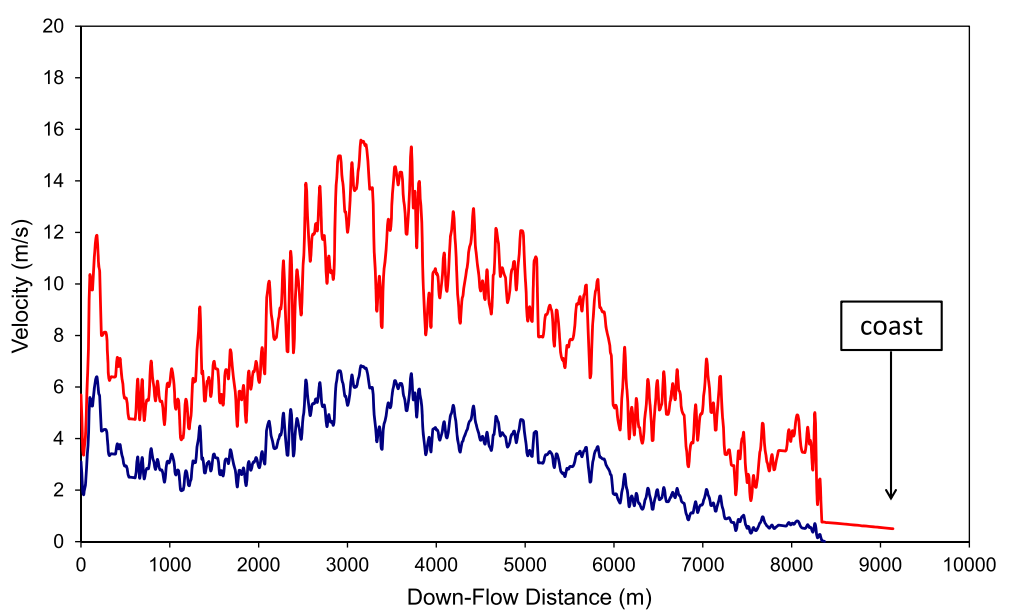

Fig. 7 FLOWGO run, in terms of velocity of lava flowing in the master channel with distance from the vent, using the first TADR values received during the May 2015 eruption. Red-line gives simulation for the maximum-bound on TADR given by MIROVA (50 $\left.\mathrm{m}^{3} / \mathrm{s}\right)$ and blue-line gives the minimum bound $\left(15 \mathrm{~m}^{3} / \mathrm{s}\right)$. While the maximum-bound attains the coast (i.e., the edge of the DEM) $9.1 \mathrm{~km}$ from the source, the minimum bound reveals a potential run-out of $8.4 \mathrm{~km}$ at $15 \mathrm{~m}^{3} / \mathrm{s}$. Model was delivered at 10:45 UT on 18 May 2015, based on TADR derived from the 10:20 UT MODIS overpass (with upper bound being based on the maximum recorded during the 19:00 UT overpass on 17 May 2015). The eruption had begun at 11:45 UT on 17 May 2015

released by melt upon ascent, decompression and degassing, and assuming that external sources (or magmatic mineral phases) do not comprise a significant fraction of the gas emission. At Piton de la Fournaise, $\mathrm{SO}_{2}$ flux has been demonstrated to scale linearly with effusion rate during small-to-intermediate volume eruptions (Hibert et al. 2015; Coppola et al. 2017). However, large volume, intense eruptions potentially degas a large volume of magma with respect to the volume erupted (Gouhier and Coppola 2011; Di Muro et al. 2014).

During the 2014-2015 eruptions, $\mathrm{SO}_{2}$ fluxes were quantified in real-time by OVPF's permanent DOAS network and through completion of walked traverses along the caldera rim. The three scanning DOAS have been installed as permanent stations, these being Partage nord, Enclos - west, and Bert - south (Galle et al. 2010). These locations are all close to the rim of the caldera, and perform continuous scanning of the sky above the Dolomieu cone during day light hours. Real-time integration of the plume cross section is performed using a set of standard and constant values for wind speed and plume height. Daily post-processing allows the spectral analysis to be refined by using the actual plume height and direction through triangulation of simultaneous scans from the three stations, and by taking into account wind speed data. During the 2014-2015 eruptions, wind speed data were provided by Meteo-France and were recorded at a station located at Bellecombe, i.e., between the DOAS stations at Partage and Enclos (see Fig. 1 for locations). Wind speed data are acquired hourly by an anemometer installed on a mast $10 \mathrm{~m}$ above the ground.
Post-processing is carried out in collaboration with Chalmers University and allows $\mathrm{SO}_{2}$ flux to be correlated with daily rain fall data, acquired by the OVPF stations, to farther constrain the environmental effects on the gas flux estimates.

While the short-lived June 2014 and July-August 2015 eruptions occurred during good weather conditions, periods of rain interrupted the longer eruptions of May 2015 and August-October 2015. Bad weather conditions were dominant during the February 2015 eruption, making any real time assessment of gas emissions unreliable during most of the event. Precise assessment of gas fluxes is also challenging during very short-lived eruptions (lasting just a few hours), especially if a significant part of the eruption occurs at night when the UV-reliant DOAS acquisition cannot be performed. DOAS sessions are acquired at a high sampling rate (one complete skyscan every $13 \mathrm{~min}$ ), but still only cover one third of a day, being limited to daylight hours (which is $<8 \mathrm{~h}$ during the winter).

TADR (bulk values) were derived from $\mathrm{SO}_{2}$ emissions using the procedure, validated for the January 2010 eruption, by Hibert et al. (2015), whereby TADR is directly proportional to the $\mathrm{SO}_{2}$ flux, and inversely proportional to the pre-eruptive gas content and degassed magma volume. This approach requires some assumptions regarding the pre-eruptive sulfur content of the magma, and on the density and vesicularity of the emitted lava. The approach becomes challenging for chemically or physically zoned eruptions, when the time evolution of magma 
chemistry, volatile content and physical properties of the erupted products requires careful estimation of the influence of these parameters on TADR estimations. For example, chemical zoning potentially translates to highly variable initial sulfur contents and produces a high uncertainty on the TADR estimate. We estimate the relative error on $\mathrm{SO}_{2}$ flux to be $\pm 22.5 \%$, where the main source of error is represented by the potentially high variability of lava vesicularity. For both the May and August-October 2015 eruptions, the best fit of estimated volumes to volumes measured by lava mapping (Peltier et al. 2016) was obtained using a low pre-eruptive sulfur content $(600 \mathrm{ppm} \mathrm{S})$, which is $55 \%$ of the content commonly assumed for undegassed magma stored in the shallow system at Piton de la Fournaise reservoir (Di Muro et al. 2014; 2016). In spite of the uncertainties in the estimations of TADR from $\mathrm{SO}_{2}$ flux, time evolution of TADR was obtained at high frequency using DOAS data and compared well with those provided by MIROVA (Fig. 8).

\section{Texture, geochemistry and petrology}

Since 1981, lava samples have been collected during or shortly after all eruptions at Piton de la Fournaise. Efforts are made to collect early-erupted lavas and tephra, and to quench molten lava in water. For geochemical measurements, samples need to be as uncontaminated as possible. During the events considered here, 110 samples were collected during or shortly after each eruption by the OVPF team. As listed in Additional file 1, they included lavas, scoria and lapilli which were both water and air quenched.

After preliminary inspection and characterization at OVPF, a representative subset of samples are mailed to LMV for textural analysis, and to LMV and IPGP for geochemical and petrological analysis. As soon as the samples arrive they are macroscopically and microscopically described, and then each sample is divided according to the needs of textural, petrological, and geochemical measurements. Time for delivery of analyses can be up to 20 days. This is mostly due to the delay imposed by sample shipping to the mainland,
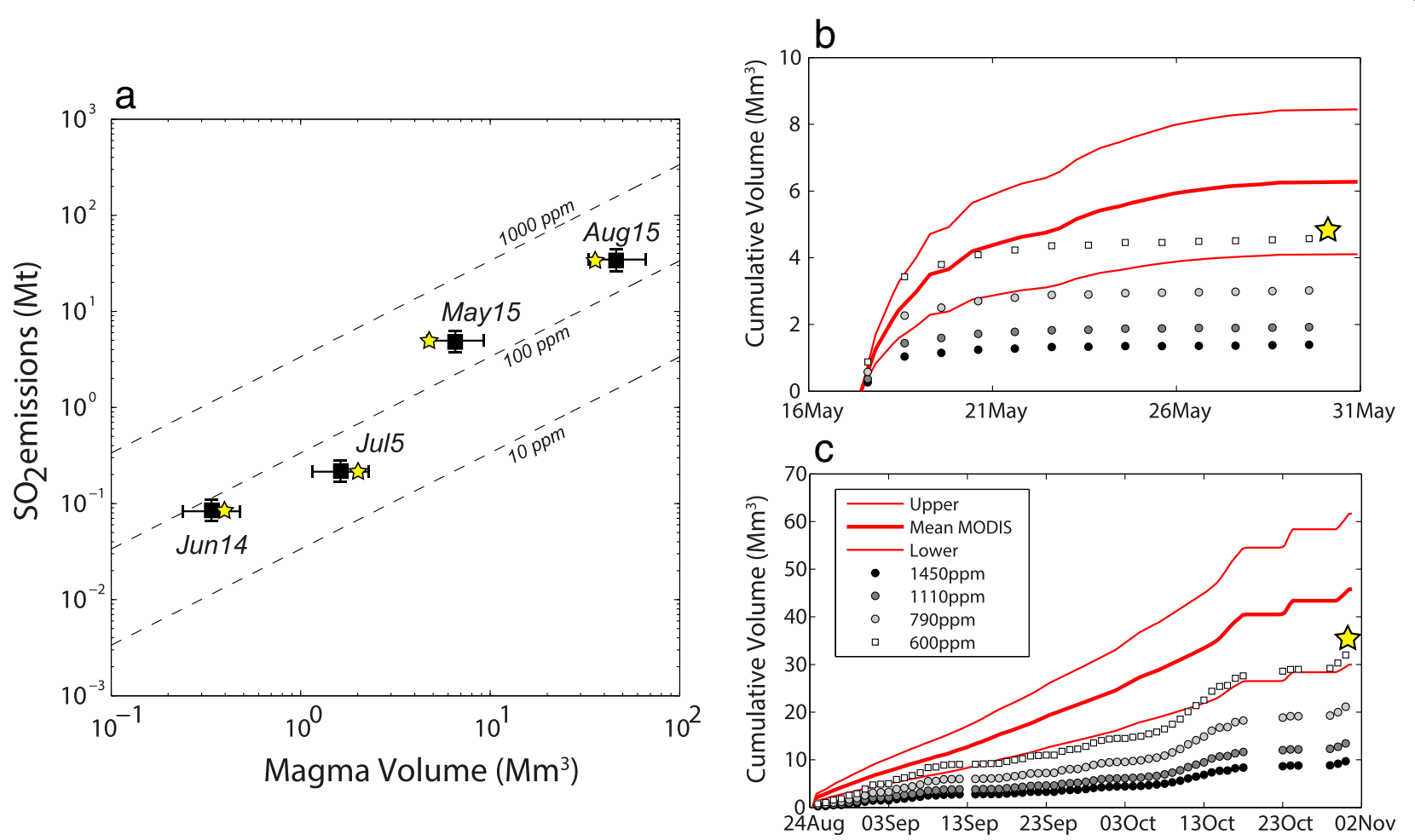

Fig. 8 a Relationships between erupted magma volume (from MIROVA) and total $\mathrm{SO}_{2}$ emissions (from NOVAC network) for four eruptions of Piton de la Fournaise (Coppola et al., submitted). Dashed lines are the theoretical relationships for initial sulfur content in the melt of 10, 100, 1000 ppm. Total $\mathrm{SO}_{2}$ emissions retrieved during short-lived eruptions (June 2014 and July 2015) were strongly underestimated because a significant part of the eruptions occurred at night. b Temporal evolution of erupted lava (bulk) volumes for the May 2015 and c August-October 2015 eruption. The cumulative volumes were derived from MODIS (red lines) and from $\mathrm{SO}_{2}$ flux, by assuming different sulfur contents in the magma (gray scale symbols). The yellow stars indicate the final lava flow volume obtained after each eruption from photogrammetry and InSAR analysis (Peltier et al. 2016). Note how the three methods converge when considering the lower estimates provided by MIROVA data and a low pre-eruptive $S$ content ( 600 ppm) for Piton de la Fournaise magmas. During each eruption, because of the uncertainty of both MIROVA and $\mathrm{SO}_{2}$-derived cumulative volumes, such comparisons were carried out in real-time to derive the mostly likely-curve on the basis of convergence, which was only achieved if adopted a low pre-eruptive $\mathrm{S}$ content 
where sample preparation and lab-time can be prioritised during an eruptive crisis reducing delays due to booking of the preparation and measurement facilities by other projects.

Samples for textural analysis are dried in an oven for $24 \mathrm{~h}$ and then used for grain size, componentry, connectivity, density, porosity and permeability measurements. Vesicle and crystal contents, as well as their size distributions, are also derived from all pyroclasts and lava samples (see Gurioli et al. (2015), Latutrie et al. (2017) and Colombier et al. (2017) for the detail regarding standard procedures, plus the meaning and application of the measurements). These measurements are performed to check variation in space (down a fissure or vent system) and in time, both within single eruptions and between different eruptions. Results are also used to check, and update if necessary, the validity of FLOWGO source terms, such as the chemistry-based rheological model, and vesicularity, density and crystal content values used by FLOWGO (Harris et al. 2016), as well as to allow $\mathrm{SO}_{2}$ emission conversions. All textural measurements are performed at the LMV textural laboratory as part of the DYNVOLC "service d'observation" (SO) or observation service (wwwobs.univ-bpclermont.fr/SO/tel evolc/dynvolc/).

For textural purposes, the first objective of sampling in active lava is to try to quench the sample so as to preserve the texture of the active flow and its chemistry (e.g., Cashman et al. 1999; Robert et al. 2014). The second objective is to be as representative of the flow source conditions, which for modelling means sampling as close to the vent as possible to allow source term validation, and then - if there is the luxury - to sample farther down channel so-as to provide ground-truth for the model in terms of cooling and crystallization rates (Harris et al. 2016). The third requirement is to be representative of the eruption itself. That is, to be sure that the at-vent thermal, chemical and textural conditions are not changing. To perform systematic observations, it is best to sample always at the flow front at the very beginning, during, and at the end of the eruption. In this way we always sample the same population. However, flow fronts are not always accessible, and to sample an active channel is not trivial; so that the reality of the situation is that we have to collect those samples that we can given difficult and challenging situations (e.g., www.youtube.com/embed/iwwV4hGVEcQ).

Whole rock major and trace element concentrations are analysed by ICP-OES and ICP-MS, respectively. Major element composition of minerals and glass are analysed by EPMA on a subset of quenched samples (naturally quenched in air or water quenched). For geochemical and petrological analysis, samples are cut into centimetre-sized chips, before being crushed into millimetre-sized chips using a set of thermally hardened steel jaws (which were not chemically doped). Finally the sample is powdered in a motorised agate mortar. To reduce cross-contamination, the first powder fraction is discarded, and the second and third powders are used for major and trace element/isotope analysis, respectively. Major elements are analysed by Inductively Coupled Plasma Optical Emission Spectrometry (ICP-OES, HORIBA Jobin Yvon Ultima C) following a Lithium metaborate $\left(\mathrm{LiBO}_{2}\right)$ fusion method, and trace elements are analysed using a Quadrupole Mass Spectrometer (ICP-MS, Agilent 7500) following acid dissolution $\left(\mathrm{HF}-\mathrm{HNO}_{3}\right)$ of the sample in teflon vials. This method allows routine analysis of 47 elements ( $\mathrm{Li}, \mathrm{Be}, \mathrm{Sc}, \mathrm{Ti}, \mathrm{V}, \mathrm{Cr}, \mathrm{Co}, \mathrm{Ni}, \mathrm{Cu}, \mathrm{Ga}, \mathrm{Ge}, \mathrm{As}, \mathrm{Rb}$, $\mathrm{Sr}, \mathrm{Rb}, \mathrm{Sr}, \mathrm{Y}, \mathrm{Zr}, \mathrm{Nb}, \mathrm{Cd}, \mathrm{In}, \mathrm{Sn}, \mathrm{Sb}, \mathrm{Cs}, \mathrm{Ba}$, Rare Earth Elements, $\mathrm{Hf}, \mathrm{Ta}, \mathrm{W}, \mathrm{Tl}, \mathrm{Pb}, \mathrm{Bi}$, Th and $\mathrm{U})$, but does not dissolve resistant minerals such as olivine-hosted $\mathrm{Cr}$ spinel. High-temperature $\left(220{ }^{\circ} \mathrm{C}\right)$ dissolution of samples with ammonium bifluoride $\left(\mathrm{NH}_{4} \mathrm{HF}_{2}\right)$ (Zhang et al. 2012) is currently being tested to overcome this issue. Routinely measured magma source tracers include $\mathrm{Sr}, \mathrm{Nd}$ and $\mathrm{Pb}$ long-lived radiogenic isotopes. Strontium and $\mathrm{Nd}$ are purified using Eichrom specific resins (Sr.Spec and Tru.Spec) and their isotopic compositions are measured by thermal ionisation mass spectrometry (TIMS Thermo Triton). Lead is separated using Biorad AG-1X8 anionic resin and its isotopic composition is measured using a Neptune plus Multi-collector ICP-MS. A detailed description of trace and isotope analytical methods is given in Vlastelic et al. (2009).

\section{Contamination problems}

An issue encountered at Piton de la Fournaise is sample contamination (for some trace elements and $\mathrm{Pb}$ isotope composition) by the tool used to collect and quench the samples. Since 1983, a zinc-coated steel (i.e., galvanized) pipe has been used (Fig. 9a), potentially contaminating samples with siderophile/chalcophile trace elements of geochemical interest, such as $\mathrm{Pb}$ and $\mathrm{Zn}$. In addition to direct contamination (Fig. 9b), which is not so problematic in the sense that the pipe mold is not used for chemical analysis, there is evidence of contamination of lava samples that have not been in direct contact with the pipe, where we have found $100-300 \mu \mathrm{m}$ metal nuggets embedded in the melt (Fig. 9c, d). This indicates that contamination occurred while the lava was still molten. The metal chips include blobs of native iron with an oxidized shell (Fig. 9c) and flakes of Zn oxide (Fig. 9d). Thin coatings of Zn (Fig. 9e) also occur at the surface of iron spherules suggesting $\mathrm{Zn}$ addition from a vapour phase, and iron-oxide coatings occur at the surface, or within vesicles, of some samples (Fig. 9f). However, the origin of the latter deposits remains uncertain as similar deposits occur in naturally quenched scoria (Vlastélic et al. 2016). Bulk trace element concentrations and $\mathrm{Pb}$ 


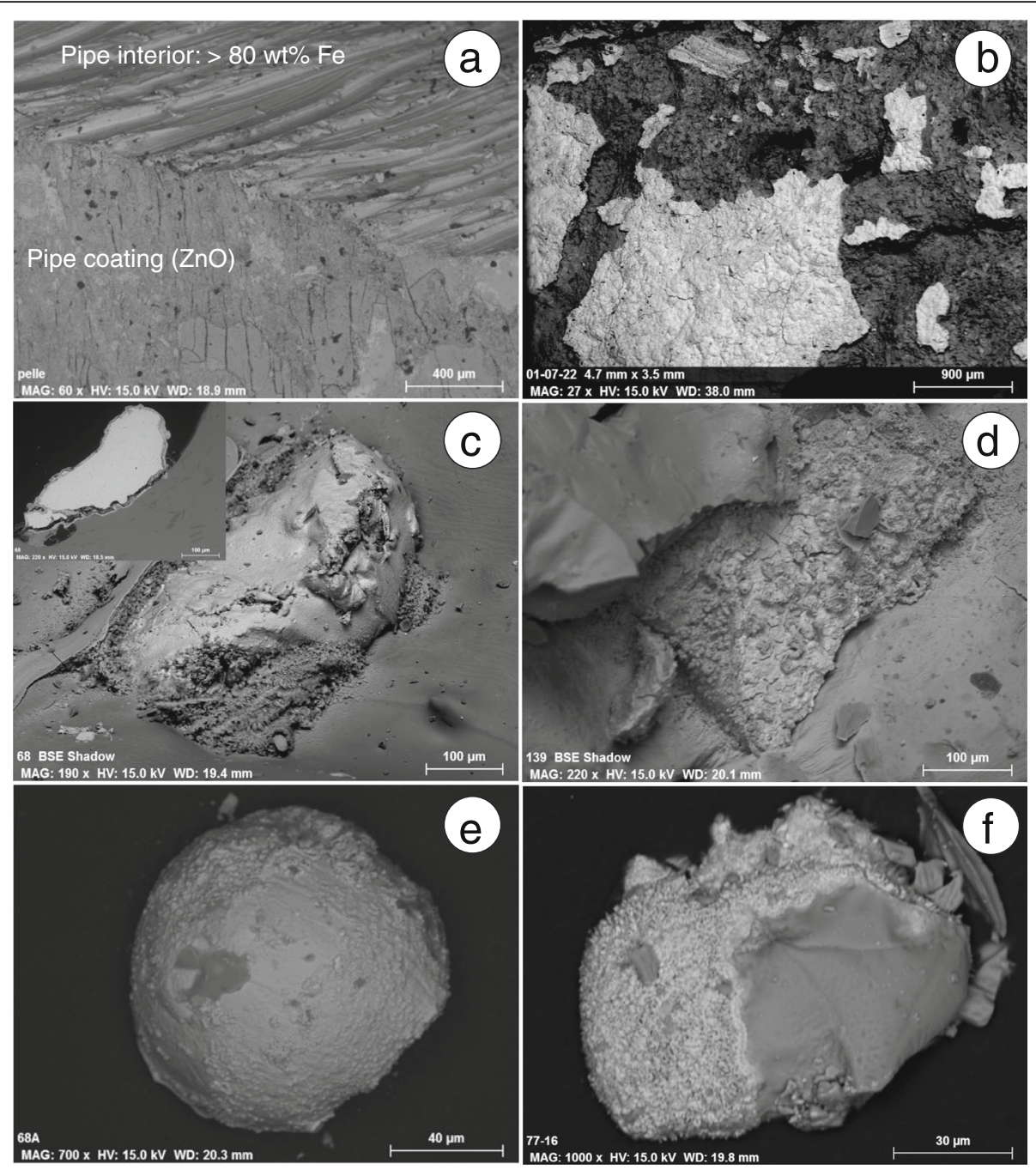

Fig. 9 Scanning Electron Microscopy (SEM) imaging of the contamination phases found in quenched lava samples. a Image of the sampling pipe showing pipe interior and Zn coating. b Iron oxide flakes on the mold of the sampling tool (sample 0107-22, July 2001). c Nugget of iron half embedded in the quenched melt. A polished section (inset) shows a grain core of metallic Fe and a thin shell of hematite (sample 030827-1, August 2003). d Flake of Zn oxide half embedded in the quenched melt (sample 070405-1, April 2007). e Iron spherule with thin Zn oxide coating (sample 030827-1, August 2003). f Silicate spherule with coating of little oxidized Fe (FeO to Fe metal) (sample 77-16, November 1977)

isotopic compositions of the pipe and the stainless steel bucket used to quench samples are given in Table 2.

Elements with the highest enrichment (E) in "pipe" relative to $\mathrm{La}$ Réunion basalts are $\mathrm{Sb}(\mathrm{E}=48)$, As $(E=38), Z n(E=21)$, Mo $(E=17), W(E=8)$, Sn $(E=4), \mathrm{Pb}$ and $\mathrm{Mn}(\mathrm{E}=2)$. Elements enriched in "bucket" are $\mathrm{Mo}(\mathrm{E}=1258), \mathrm{Ni}(\mathrm{E}=967), \mathrm{Cr}(\mathrm{Ni}=830)$, W $(E=575), S b(E=154), A s(E=86), S n(E=74)$, Co $(E=38), \mathrm{Cu}(\mathrm{E}=12)$ and $\mathrm{Mn}(\mathrm{E}=10)$. Magnetic fractions separated from recent (2001-2007) quenched samples have elevated $\mathrm{Zn}-\mathrm{Pb}$ concentrations (up to $13 \%$ for $\mathrm{Zn}$ and $450 \mathrm{ppm}$ for $\mathrm{Pb}$ ). These values exceed those measured in the bulk pipe $(0.23 \%$ for $\mathrm{Zn}$, and $3.6 \mathrm{ppm}$ for $\mathrm{Pb}$ ) (Fig. 10). This rules out bulk assimilation of pipe material and suggests either preferential input of the galvanized coating (made essentially of $\mathrm{Zn}$ ) or deposition of a vapor phase enriched in $\mathrm{Zn}$ and $\mathrm{Pb}$. The $\mathrm{Pb}$ isotopic signature of the magnetic fractions separated from quenched lava samples, as well as those of the pipe and the bucket are given in ${ }^{207} \mathrm{~Pb} /{ }^{204} \mathrm{~Pb}$ versus ${ }^{206} \mathrm{~Pb} /{ }^{204} \mathrm{~Pb}$ isotope space in Fig. 11a. The compositions of the magnetic fractions plot along well-defined mixing lines between lavas and three distinct contaminants. It is clear that lavas quenched between 2003 and 2007 were contaminated by the pipe. The 2001 contaminant had higher ${ }^{207} \mathrm{~Pb} /{ }^{204} \mathrm{~Pb}$ and $\mathrm{Zn}-\mathrm{Pb}$ concentrations compared with the bulk pipe. We expect this contaminant to be the $\mathrm{Zn}$ coating of the pipe, although we have not measured its $\mathrm{Pb}$ isotopic composition. The change of contaminant between 2001 and 2003, despite the use of the 
Table 2 Trace element and $\mathrm{Pb}$ isotopic composition of the tools used to collect and quench molten lava since 1998

\begin{tabular}{|c|c|c|c|c|c|}
\hline & Basalts & Pipe & $\begin{array}{l}\text { Pipe/ } \\
\text { Basalt }\end{array}$ & Bucket & $\begin{array}{l}\text { Bucket/ } \\
\text { Basalt }\end{array}$ \\
\hline & (ppm) & (ppm) & (ratio) & (ppm) & (ratio) \\
\hline Sc & 33 & 1.4 & 0 & 2.2 & 0 \\
\hline $\mathrm{Ti}$ & 16,130 & 28.9 & 0 & 7.7 & 0 \\
\hline V & 300 & 5.9 & 0 & 842 & 3 \\
\hline $\mathrm{Cr}$ & 225 & 149 & 1 & 186,609 & 830 \\
\hline $\mathrm{Mn}$ & 1400 & 2582 & 2 & 13,888 & 10 \\
\hline Co & 45 & 14.4 & 0 & 1718 & 38 \\
\hline $\mathrm{Ni}$ & 92 & 74.1 & 1 & 89,063 & 967 \\
\hline $\mathrm{Cu}$ & 104 & 72.3 & 1 & 1226 & 12 \\
\hline $\mathrm{Zn}$ & 110 & 1527 & 14 & 0.0 & 0 \\
\hline $\mathrm{Ga}$ & 22 & 9.0 & 0 & 31 & 1 \\
\hline As & 0.8 & 31.6 & 38 & 71 & 86 \\
\hline $\mathrm{Sr}$ & 353 & 0.6 & 0 & 3.9 & 0 \\
\hline $\mathrm{Zr}$ & 193 & 0.2 & 0 & 0.2 & 0 \\
\hline $\mathrm{Nb}$ & 22 & 0.3 & 0 & 10.2 & 0 \\
\hline Mo & 1 & 13.8 & 17 & 1006 & 1258 \\
\hline $\mathrm{Cd}$ & 0.250 & 0.0 & 0 & 0.77 & 3 \\
\hline $\ln$ & 0.085 & 0.0 & 0 & 0 & 5 \\
\hline Sn & 1.8 & 7.7 & 4 & 136 & 74 \\
\hline $\mathrm{Sb}$ & 0.1 & 3,2 & 48 & 10.1 & 154 \\
\hline $\mathrm{Ba}$ & 136 & 1.9 & 0 & 0.2 & 0 \\
\hline W & 0.3 & 2.4 & 8 & 169 & 575 \\
\hline $\mathrm{Pb}$ & 1.7 & 3.6 & 2 & 0.4 & 0 \\
\hline${ }^{206} \mathrm{~Pb} /{ }^{204} \mathrm{~Pb}$ & $18.87-18.94$ & 16.937 & & 18.436 & \\
\hline${ }^{207} \mathrm{~Pb} /{ }^{204} \mathrm{~Pb}$ & $15.585-15.602$ & 15.401 & & 15.630 & \\
\hline${ }^{208} \mathrm{~Pb} /{ }^{204} \mathrm{~Pb}$ & $38.96-39.04$ & 36.869 & & 38.444 & \\
\hline
\end{tabular}

$\mathrm{Pb}$ isotopic compositions are relative to NBS 981 values: ${ }^{206} \mathrm{~Pb} / 204 \mathrm{~Pb}=16.9356$, ${ }^{207} \mathrm{~Pb} /{ }^{204} \mathrm{~Pb}=15.4891,{ }^{208} \mathrm{~Pb} /{ }^{204} \mathrm{~Pb}=36.7006$

same tool, is consistent with progressive abrasion of the galvanized coating. The 1977 contaminant is even higher in terms of ${ }^{207} \mathrm{~Pb} /{ }^{204} \mathrm{~Pb}$ (Fig. 9a). The occurrence of small $\mathrm{Fe}-\mathrm{Cr}-\mathrm{Ni}$ shavings (68 wt.\% $\mathrm{Fe}, 18$ wt.\% $\mathrm{Cr}$ and 9 wt.\% Ni) points to stainless steel as being the cause. We hypothesize that contamination arose from the use of a K-type (chromel/alumel) thermocouple (Boivin and Bachèlery 2009), whose mold was found in some quenched samples. This source of contamination does, thus, not apply to 1977, 1979 and 1981 samples because the first K-type thermocouple was not used on Piton de la Fournaise until December 1983. To date, contamination with the sampling tool results in spikes in $\mathrm{Zn}$ concentration and $\mathrm{Pb}$ isotopes that superimpose on the otherwise smooth temporal trend (Fig. 11b). Solutions that are currently envisioned to reduce or suppress contamination include the use of high temperature resistant ceramics, or a tool made of natural basalt from Piton de la Fournaise.

\section{Results}

In total 127 TADR values were derived and delivered to OVPF by the MIROVA system during the 2014-2015 crises, cloud cover meaning that reporting varied between zero and four TADRs per day; with an average of two per day during the August-October 2015 eruption. During the five 2014-2015 eruptions, the results of 31 sample analyses, plus all DOWNFLOW and FLOWGO model runs were delivered directly to OVPF. All measurements and products were cross-checked, and merged with data fed back into the communication loop by the monitoring system operated by OVPF. This allowed source term update, uncertainty control and validation, as well as fully constrained event tracking.

\section{MIROVA-derived TADR and cumulative volume}

For the duration, erupted volume, peak TADR and mean output rate (MOR), there was a general tendency of increase between each of the five eruptions (Table 3). That is, the first eruption had the smallest intensity and magnitude, and the last eruption had the largest, peaking at a maximum TADR of $59 \mathrm{~m}^{3} / \mathrm{s}$. During the whole sequence of eruptions the MOR increased almost linearly,

$$
\begin{aligned}
\text { MOR } & =1.95(\text { eruption } \#)-0.80 \\
R^{2} & =0.731 \text { (fit is for the range mid-point) }
\end{aligned}
$$

The first four events had TADR and cumulative volume trends (e.g., Fig. 5) that displayed the classic rapid waxing and waning forms that characterize the eruption of a pressurized source, as defined by Wadge (1981). However the stable, generally flat trend (after a short initial peak) of the final and long lasting eruption is more typical of that witnessed during an eruption that taps an unpressurized source (Harris et al. 2000b). The final eruption did, though, undergo an increase from $7.2 \pm 1.4 \mathrm{~m}^{3} / \mathrm{s}$ between 25 August and 12 October 2015 to $15.9 \pm 4.1 \mathrm{~m}^{3} / \mathrm{s}$ between 13 and 17 October (Fig. 12). The two TADR spikes, or reactivations of the eruption, on 23 and 30 October record two short-events with peaks at 32 and $20 \mathrm{~m}^{3} / \mathrm{s}$, respectively, at the end of the eruption. Both of these two events, plus the peak that ended the main phase of effusion which was centered on 16 October, were interrupted by abrupt cessations of lava effusion. Each peak was separated by exactly 7 days and lasted for 2 days.

Viewing of the flow field on 23-24 October was complicated by a wild fire that was burning on the caldera wall and in the same pixel (s) as the cooling flow field. The fire was ignited by lava contact at the base of the 


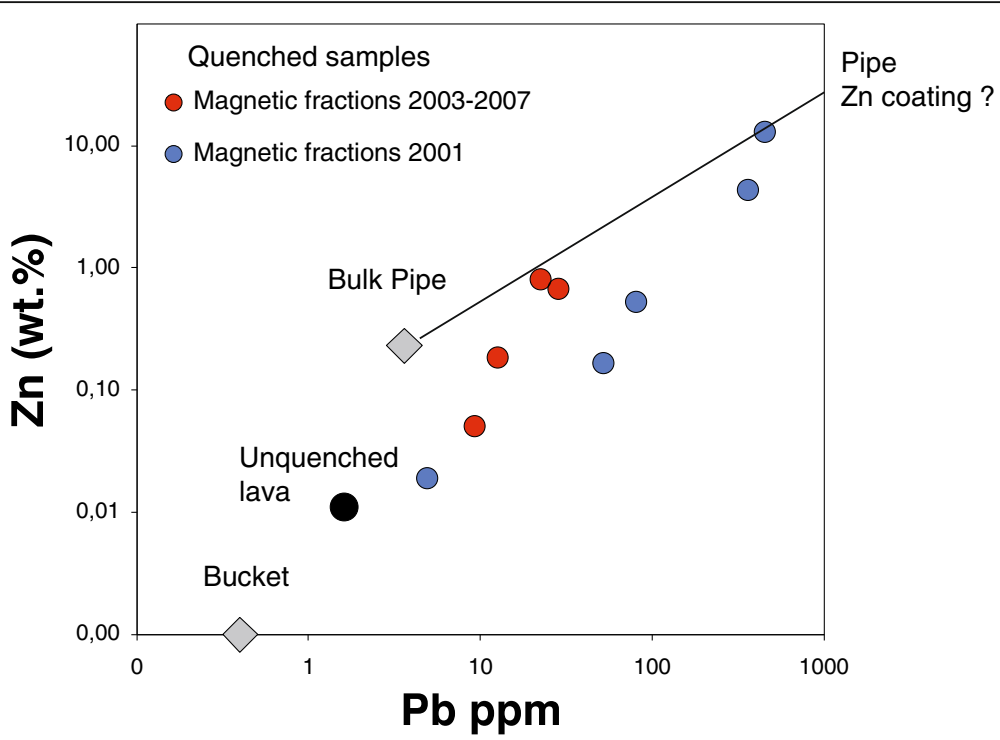

Fig. $10 \mathrm{Zn}-\mathrm{Pb}$ concentration plot. Compositions of the magnetic fractions separated from quenched samples are here compared with that of the bulk composition of the pipe, the bucket and unquenched lavas. The expected composition of the Zn coating of the pipe (not measured) is indicated (80 wt.\% Zn, 0.4\% wt\% Pb)

caldera wall around 13:00 on 23 October and quickly spread up the wall, requiring rapid evacuation of footpaths and viewing points (Le Journal de L'Ile de la Réunion, 24 October 2015, p. 4). Landsat ETM+ images acquired after the event revealed a $0.2 \mathrm{~km}^{2}$ $(1000 \times 200 \mathrm{~m})$ burn scar. However, given an estimate of 100-300 MW for the fire radiative power, the contribution to the total radiative power (2000-6000 MW) was not significant, and of the order of the uncertainty due to the contribution from cooling lava flows emplaced during the main phase of activity (400-500 MW).

\section{Textural characterization and geochemical evolution}

Quenched lava samples erupted during June 2014 to August-October 2015 were characterized by a mean porosity of $51 \%$ with a standard deviation of $15 \%$ (Fig. 13a), where all calculations are based on the DRE (dense rock equivalent) measurement of $2.88 \times 10^{3} \mathrm{~kg} \mathrm{~m}^{-3}$. Two extreme points (with porosities of $16 \%$ and $86 \%$ ) were measured measured on the first day of the AugustOctober 2015 eruption and then on 15 September 2015, respectively. Otherwise, the most degassed lava sample was obtained from the June 2014 eruption (Fig. 13a). When compared with the porosity values obtained for 450 coarse lapilli, which ranged from 36 to $86 \%$, the lava values were comparable to this range. For crystallinity, we analyzed a lava sample with a porosity of $50 \%$ from the July 2015 eruption (Fig. 13b). This was characterized by a crystallinity of $20 \%$, which mainly comprised mesocrystals of plagioclase (up to $3 \mathrm{~mm}$ in diameter), clinopyroxene (up to $2 \mathrm{~mm}$ ) and scarce olivine (+ spinel inclusions) in a glassy matrix with microcrystals of the same paragenesis (Fig. 13b, c). Measured ranges were consistent with parameters (vesicularity: 49\%; melt density: $2.80 \times 10^{3} \mathrm{~kg} \mathrm{~m}^{-3}$ ) selected for conversion of $\mathrm{SO}_{2}$ fluxes in lava output rates.

July 2015 lava samples were aphyric basalts that mainly contained clinopyroxene and plagioclase microphenocrysts $(<500 \mu \mathrm{m})$ with rare olivine microphenocrysts set in a glassy or fine-grained matrix. Lavas emitted at the beginning of the August-October 2015 eruption had the same modal composition as those of July 2015, with microphenocrysts mainly of clinopyroxene and plagioclase set in a glassy-to-microlitic groundmass. After 15 September (the date on which the porosity trend turned around from its minimum value, Fig. 13a), a change in magma composition became evident as olivine mesocrysts became more frequent, and plagioclase microphenocrysts disappeared between 15 and 27 September (an exception being the lavas of 9 October). Thus, from the end of September until the beginning of October, lavas were aphyric basalts with clinopyroxene and olivine microphenocrysts and mesocrysts. From 9 October onwards, clinopyroxene was no longer observed as microphenocrysts, and only olivine microphenocrysts and mesocrysts (with Cr-spinels in inclusion) were observed. From mid-October to the end of the eruption, lavas were olivine basalts that contained $5-10 \%$ of olivine crystals ( $>500 \mu \mathrm{m}$, up to $6 \mathrm{~mm}$ in size) set in a matrix containing microlites of clinopyroxene, olivine and plagioclase (+ glass).

Lavas erupted between June 2014 and May 2015 underwent a decreasing trend in $\mathrm{MgO}$ (6.6-6.1 wt\%), $\mathrm{Cr}$ (87-58 ppm) and $\mathrm{CaO} / \mathrm{Al}_{2} \mathrm{O}_{3}$ (from 0.78 to 0.73 ) 

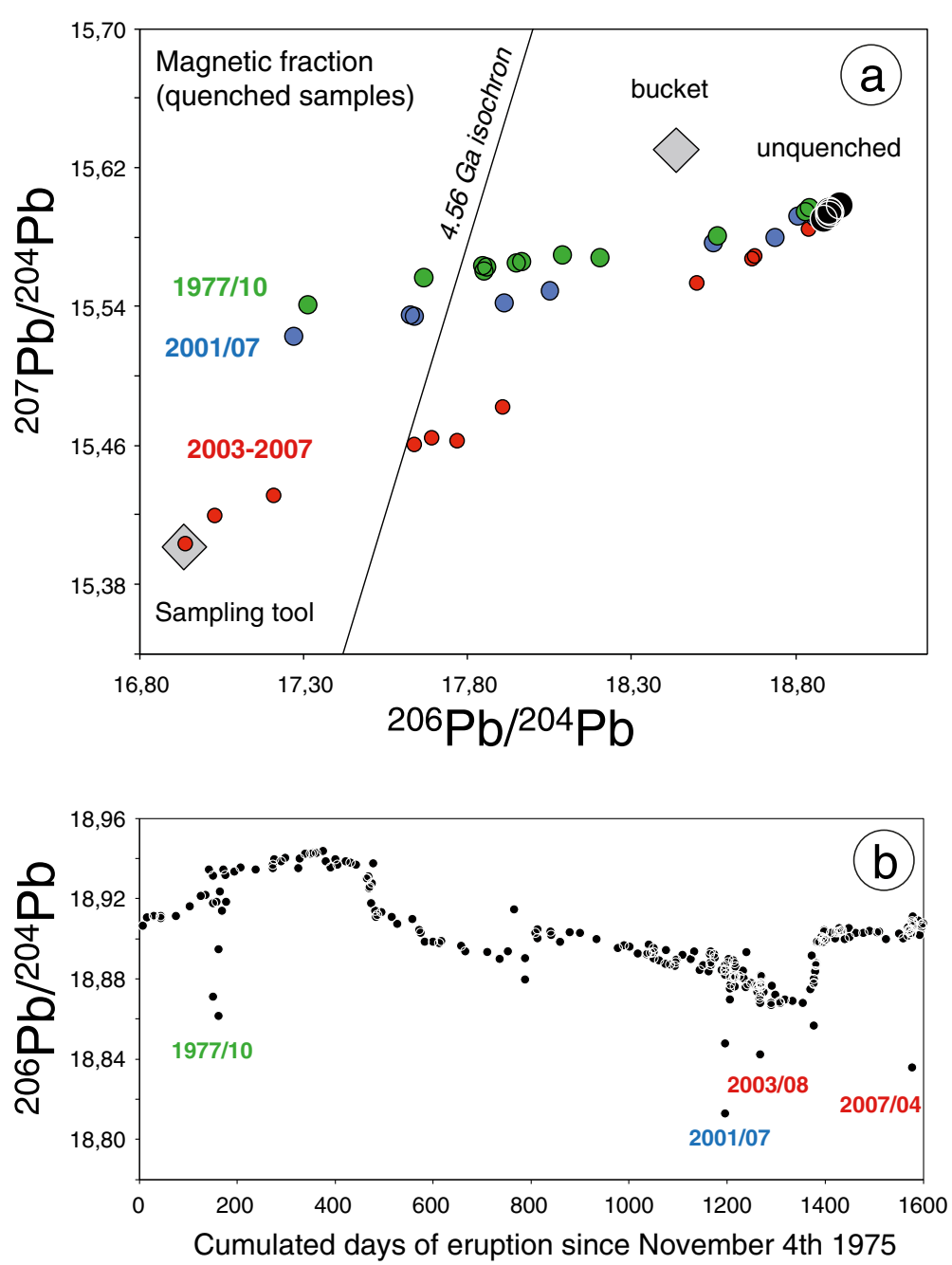

Fig. 11 Lead isotope plots. a ${ }^{207} \mathrm{~Pb} /{ }^{204} \mathrm{~Pb}$ versus ${ }^{206} \mathrm{~Pb} /{ }^{204} \mathrm{~Pb}$ plot showing the composition of the magnetic fractions separated from quenched lava samples, the bulk compositions of the pipe, the bucket and unquenched lavas. $\mathbf{b}$ Temporal evolution of ${ }^{206} \mathrm{~Pb} /{ }^{204} \mathrm{~Pb}$ in Piton de la Fournaise lavas. Unradiogenic Pb spikes in October 1977, July 2001, August 2003 and April 2007 result from the contamination of quenched samples

(Fig. 14). The lavas erupted on 17 and 18 May 2015 were amongst the most differentiated of the historical period, resembling those produced in March 1998 after 5.5 years of quiescence (Vlastélic et al. 2005). This was consistent with the low-pre-eruptive $\mathrm{S}$ content of these lavas deduced on the basis of $\mathrm{SO}_{2}$ fluxes. However, a change in behaviour occurred during the May 2015 eruption when the
$\mathrm{MgO}, \mathrm{Cr}, \mathrm{CaO} / \mathrm{Al}_{2} \mathrm{O}_{3}$ temporal trends reversed between 18 and 24 May. The new trend was, at first, subtle but became more evident during the subsequent eruption of July-August 2015 and, especially, August-October 2015 (Fig. 14): the long-lived August-October eruption underwent a compositional evolution of $\mathrm{MgO}$ from 6.6 to $10.3 \mathrm{wt} \%$. Inspection of $\mathrm{Ni}-\mathrm{Cr}$ suggested that cumulative

Table 3 Statistics for the MIROVA-derived eruption parameters for, and total $\mathrm{SO}_{2}$ mass emitted during, each eruption

\begin{tabular}{|c|c|c|c|c|c|c|}
\hline Eruption & $\begin{array}{l}\text { Duration } \\
\text { (days) }\end{array}$ & $\begin{array}{l}\text { No. cloud-free } \\
\text { MODIS images }\end{array}$ & $\begin{array}{l}\text { Peak TADR } \\
\left(\mathrm{m}^{3} / \mathrm{s}\right)\end{array}$ & $\begin{array}{l}\text { Volume } \\
\left(\times 10^{6} \mathrm{~m}^{3}\right)\end{array}$ & $\begin{array}{l}\text { Mean Output } \\
\text { Rate }\left(\mathrm{m}^{3} / \mathrm{s}\right)\end{array}$ & $\begin{array}{l}\mathrm{SO}_{2} \text { mass } \\
(\mathrm{kt})\end{array}$ \\
\hline June 2014 & 2 & 3 & 7.4 & 0.34 & 2.1 & 0.09 \\
\hline February 2015 & 12 & 8 & 1.8 & 0.82 & 0.8 & - \\
\hline May 2015 & 14 & 24 & 37 & 6.5 & 5.6 & 4.80 \\
\hline July-August 2015 & 2 & 7 & 22 & 1.6 & 9.2 & 0.22 \\
\hline August-October 2015 & 69 & 92 & 59 & 45 & 7.6 & 33.80 \\
\hline
\end{tabular}




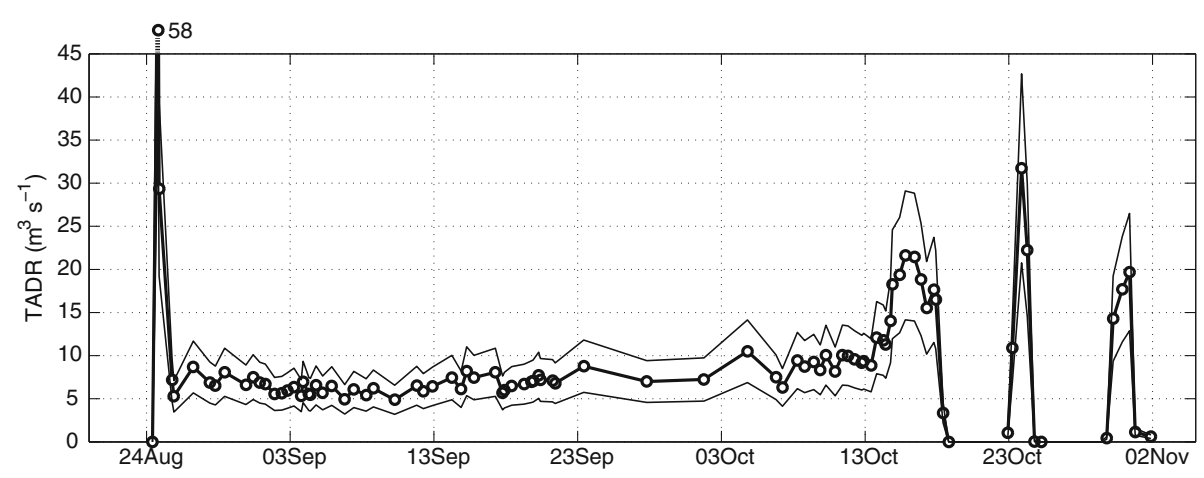

Fig. 12 MIROVA-derived TADRs (circles) and related uncertainty (thin solid lines) recorded during the August - October 2015 eruption

olivine occurred in the lavas erupted between 16 and 26 October, which had $\mathrm{MgO}$ contents in excess of $9 \mathrm{wt} \%$. The last sample analysed that contained no evidence for cumulative olivine was erupted on 9 October, and had $8.0 \mathrm{wt} \% \mathrm{MgO}, 122 \mathrm{ppm} \mathrm{Ni}$ and $302 \mathrm{ppm} \mathrm{Cr}$, indicating the occurrence of a relatively primitive melt.

These changes in chemistry had little effect on the modelled lava flow run-outs, with TADR being the main determinate on controlling FLOWGO-derived run-out. Likewise, textural changes were within the error of source parameters set using the 2010 eruption conditions (Harris et al. 2015). However, following the time evolution of bulk magma composition was critical for the interpretation of time evolution of TADR, which increased during the second half of August eruption, concomitantly with the emission of more magnesian basalts.
What the evolution of the geochemical and textural parameters did show was that the system was evolving towards an unloading scenario to result in a terminating effusive "paroxysm" which, in hind sight, signalled the end of this particular cycle (Coppola et al. 2017).

\section{Validation}

FLOWGO was validated through comparison of simulated flow lengths with actual flow lengths. Best data for comparison were achieved during the August-October 2015 eruption, during which cooling-limited flow regimes became established, as opposed to the volumelimited cases of the shorter duration eruptions when the eruption ended while flow fronts were still extending. On 2 September field-observations revealed that flow lengths were around $1 \mathrm{~km}$, and $2 \mathrm{~km}$ by 4 September.
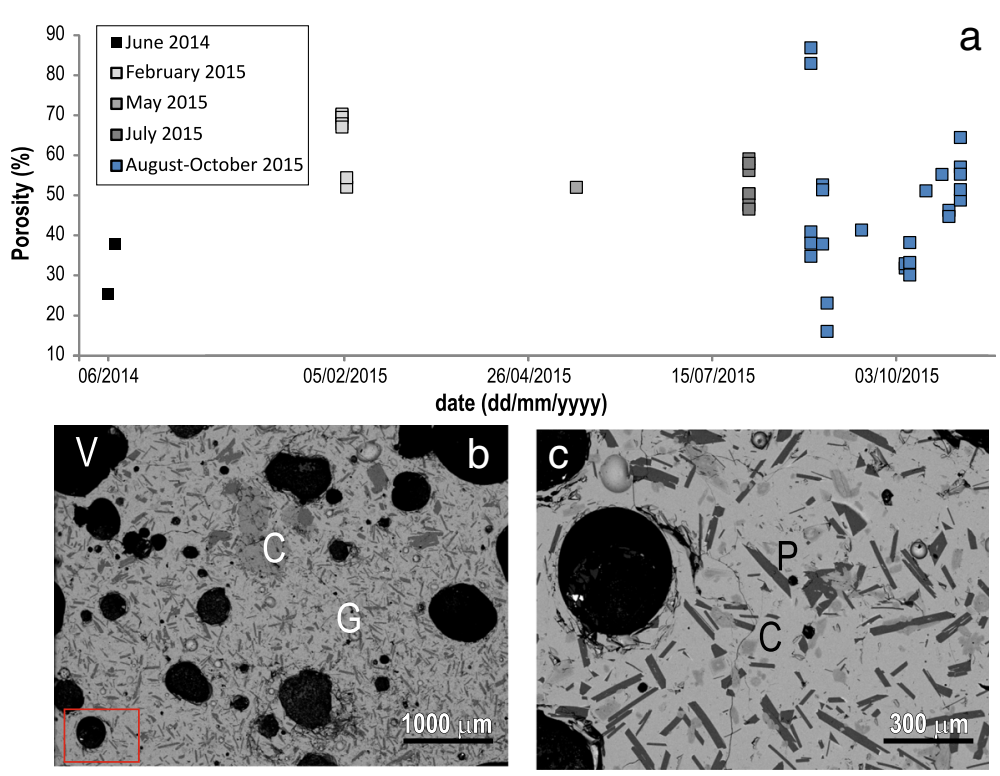

Fig. 13 a Porosity versus time for quenched lava fragments collected during the 2014 and 2015 eruptive events at Piton de La Fournaise; b BSE (Back-Scattered Electron Imaging mode) image of a quenched sample from the July 2015 lava flow, in which: $V=$ vesicles; $C=$ mesocrystals of plagioclase and clinopyroxene; $G$ = glass plus microcrystals of plagiolase, clinopyroxene and olivine; c zoom of the area identified in (b) by the red rectangle, where $\mathrm{P}=$ plagioclase and $\mathrm{C}=$ clinopyroxene 


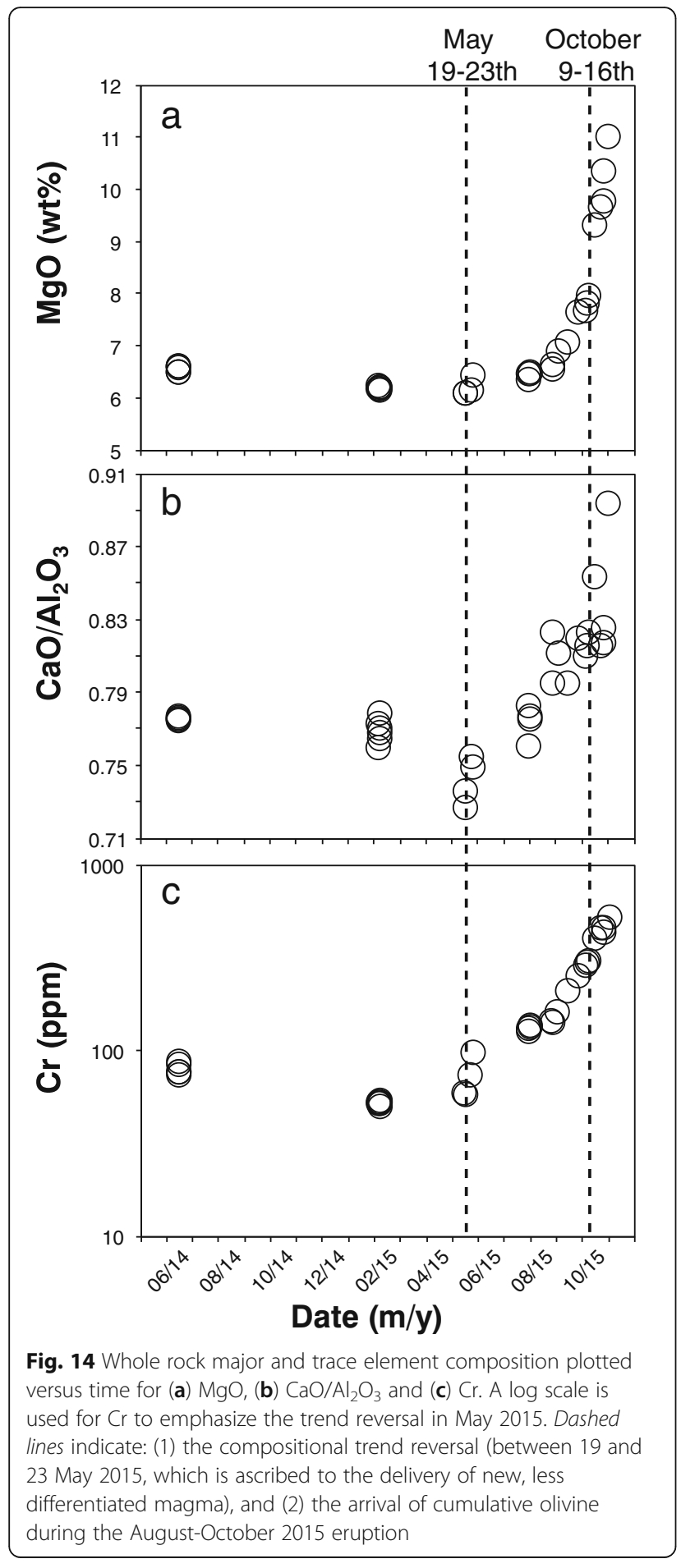

When run at the MIROVA-derived TADR for this period of around $3.5-4.5 \mathrm{~m}^{3} / \mathrm{s}$, we obtained a FLOWGO run out of around 1.25-2 km (Fig. 15). During the eruption, this approach was thus used in a circular fashion. That is: if the TADRs input into the model produced run outs that agreed with ground truth, then we have confidence in the TADRs used to initialize the model run. The good agreement between TADR-derived FLOWGO run-outs and observed run outs gave us confidence in (i) the TADR entered into the model, and then (ii) the model. The combination of TADR and flow model, at the very-least, were giving reliable run out estimates, such that we had confidence in the next run-out estimate should TADR increase.

After the eruption, FLOWGO run outs were checked against flow lengths derived from InSAR mapping (Table 4). Based on satellite overpasses, maps of the lava flow were produced for eight dates during, and after the end of, the eruption. Maps were derived from interferometric coherence maps following the approach developed by Zebker et al. (1996), Dietterich et al. (2012) and Bato et al. (2016). For each date, the length of all main lava flow branches active between each overpass were estimated using a stochastic maximum slope path approach so as to find the flow center-line between the source and the flow front and to extract its distance (e.g., Favalli et al. 2005). The InSAR analysis revealed that, between 29 September and 13 October 2015, lava flows were cooling-limited where, under a relatively stable TADR, units were extending to $3.6-3.9 \mathrm{~km}$ before stalling so that the following flow was emplaced next to the preceding unit. This built a broad, branching flow field with a low aspect (length/width) ratio, typical of long-lived eruptions at stable TADRs that feed sequential cooling-limited units (Kilburn and Lopes 1988). At this time, FLOWGO run outs were in good agreement with the mapped lengths, being in the range $3-4 \mathrm{~km}$ depending on TADR (Table 4). This comparison reveals that differences between FLOWGO-simulated and InSAR-mapped run outs for this event were $0.1-0.8 \mathrm{~km}$ or $3-20 \%$. During the short-lived TADR spikes of 17 and 24. October 2015, FLOWGO run outs were much longer than measured-flow lengths (Table 4). This was a result of these events being volume-limited, so that supply was cut before flow could attain its maximum potential distance (Guest et al. 1987), with FLOWGO simulating the cooling-limited length a flow can attain IF supply is maintained for a time sufficient for the flow to attain its maximum potential length.

Measurements to support validation of MIROVAderived TADR were also made during the July-August 2015 eruption. Observations were made of the main active vent and its outlet channel between 10:00 and 15:00 on 1 August 2015. In addition, thermal video was taken at the head of the master channel where it exited the eruptive fissure for $5 \mathrm{~min}$ at 11:40 on 1 August, and a water-quenched sample was collected from the same location at 13:15. The channel was $2 \mathrm{~m}$ wide and contained a $2 \mathrm{~m}$ deep flow with its surface $1 \mathrm{~m}$ below the levee rim. Velocities obtained from the thermal video were $0.05-0.1 \mathrm{~m} / \mathrm{s}$, for an effusion rate of $0.2-$ $0.4 \mathrm{~m}^{3} / \mathrm{s}$. This agrees with MIROVA-derived TADRs 


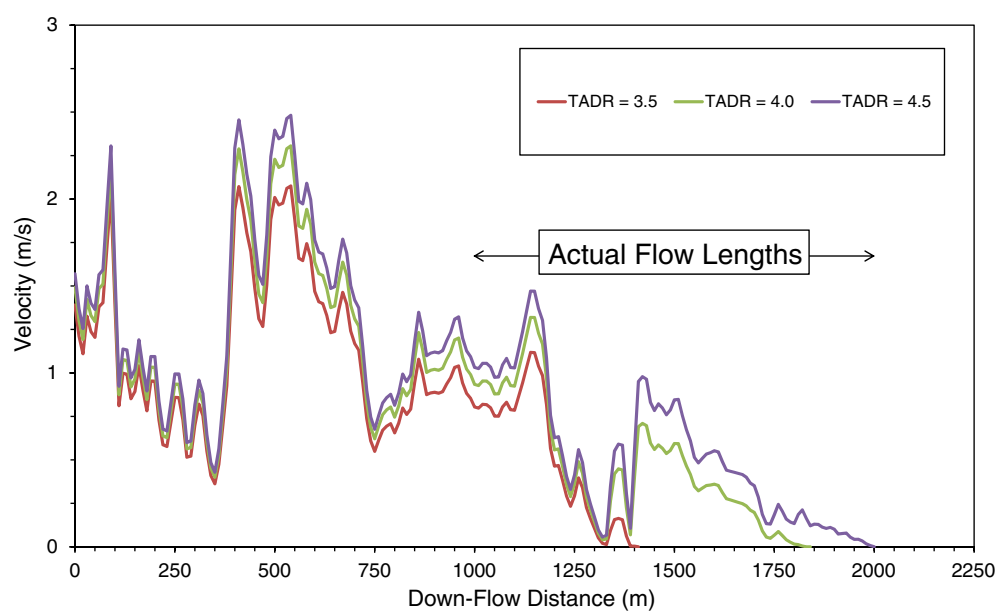

Fig. 15 FLOWGO run, in terms of velocity of lava flowing in the master channel with distance from the vent, using the first TADR values (in $\mathrm{m}^{3} / \mathrm{s}$ ) received from MIROVA during 2-4 September 2015, along with field-measured flow lengths for the same period. FLOWGO run outs, marked by the point where velocity reaches zero, i.e., the lava control volume has stopped, fall within the range of field measurements

of $0.8 \pm 0.4 \mathrm{~m}^{3} / \mathrm{s}$ obtained from the two evening MODIS overpasses at 19:25 and 20:55 on 1 August, and with the value of $0.18 \pm 0.6 \mathrm{~m}^{3} / \mathrm{s}$ obtained on 2 August at 06:20, $5 \mathrm{~h}$ before the eruption ended. Because our observations were made during a period of waning activity, where flow levels and velocities in the master channel underwent a noticeable decline after 11:30 on 1 August, we used Jeffreys (1925) to estimate flow velocities under peak-flow conditions. Viscosity was calculated on the basis of thermalcamera-derived flow temperature $\left(1114{ }^{\circ} \mathrm{C}\right)$, plus sample crystal (19-20\%) and/or vesicle (50-58\%) content, using Villeneuve et al. (2008), Roscoe (1952), Manga and Loewenberg (2001), Pal (2003) and Llewellin and Manga (2005). Results were in the range $370-700 \mathrm{~Pa}$ s. Using this viscosity range in Jeffreys (1925), with the sample density of $1510 \mathrm{~kg} / \mathrm{m}^{3}$ and underlying slope of $5^{\circ}$, yields a peak-flow velocity of $0.9-1.7 \mathrm{~m} / \mathrm{s}$, for an effusion rate of $5.35 \pm 1.65 \mathrm{~m}^{3} / \mathrm{s}$. This matches the MIROVA-derived TADR of $6.25 \pm 2.25 \mathrm{~m}^{3} / \mathrm{s}$ for 10:00 on 1 August. Aerial photographs taken by journalists during the opening day of the eruption $(\mathrm{H}$. Douris, Le Journal de L'Ile de la Réunion, 02/08/15, p. 7) reveals the master channel to have been brim full (i.e., flow depth $=3 \mathrm{~m}$ ) at that point. This higher flow level yields velocities of $2.1-3.9 \mathrm{~m} / \mathrm{s}$, which convert to effusion rates of $12 \pm 3.7 \mathrm{~m}^{3} / \mathrm{s}$. The same photographs indicated that two channel systems of similar dimensions were active during 31 July, so the total effusion rate could have been as high as $24 \pm 8 \mathrm{~m}^{3} / \mathrm{s}$ during the opening hours of the eruption. These values again compare well with those derived from MIROVA which gave $22 \pm 8 \mathrm{~m}^{3} / \mathrm{s}$ from MODIS images acquired at 18:40 and $21: 50$ on 31 July.

Table 4 MIROVA-derived time-averaged discharge rate (TADR) for dates on which InSAR data are available with FLOWGO lava flow run-outs that each TADR gives and the InSAR-derived lava flow length for the same day. $\Delta$ gives the difference between the InSARderived flow length and FLOWGO run-out

\begin{tabular}{|c|c|c|c|c|}
\hline Date & $\begin{array}{l}\text { MIROVA-derived } \\
\text { TADR }\left(\mathrm{m}^{3} / \mathrm{s}\right)\end{array}$ & $\begin{array}{l}\text { FLOWGO run-out } \\
(\mathrm{km})\end{array}$ & $\begin{array}{l}\text { InSAR-derived } \\
\text { flow length }(\mathrm{km})\end{array}$ & $\begin{array}{l}\Delta \\
(\mathrm{km})\end{array}$ \\
\hline 29 August 2015 & $8.1 \pm 2.8$ & $3.1 \pm 0.4$ & $3.9 \pm 0.2$ & $0.8 \pm 0.6$ \\
\hline 14 September 2015 & $6.8 \pm 2.3$ & $3.0 \pm 0.1$ & $3.7 \pm 0.1$ & $0.7 \pm 0.2$ \\
\hline 30 September 2015 & $7.1 \pm 2.5$ & $3.0 \pm 0.2$ & $3.7 \pm 0.1$ & $0.7 \pm 0.3$ \\
\hline 04 October 2015 & $10.5 \pm 3.6$ & $3.5 \pm 0.5$ & $3.6 \pm 0.1$ & $0.1 \pm 0.6$ \\
\hline 08 October 2015 & $9.1 \pm 3.1$ & $3.1 \pm 0.6$ & $3.7 \pm 0.1$ & $0.6 \pm 0.7$ \\
\hline 13 October 2015 & $10.5 \pm 3.6$ & $3.5 \pm 0.5$ & $3.6 \pm 0.1$ & $0.1 \pm 0.6$ \\
\hline 17 October 2015 & $24.8 \pm 8.5$ & $9.7 \pm 1.6$ & $5.6 \pm 0.1$ & $4.1 \pm 1.7$ \\
\hline 24 October 2015 & $22.2 \pm 3.8$ & $8.7 \pm 1.2$ & $5.7 \pm 0.5$ & $3.0 \pm 1.7$ \\
\hline 01 November 2015 & $0.6 \pm 0.2$ & $0.4 \pm 0.1$ & $5.7 \pm 0.5$ & $5.3 \pm 0.6$ \\
\hline
\end{tabular}


The response: An example from the may 2015 eruption The May 2015 eruption began at 13:45 (local time) on 17 May at three en-echelon fissures. The shortest $(30 \mathrm{~m}$ long) and most western fissure was located at $2285 \mathrm{~m}$ asl. The second fissure was located $200 \mathrm{~m}$ farther east, between 2250 and $2100 \mathrm{~m}$ asl, and was $500 \mathrm{~m}$ long. The third, and most eastern, fissure was located a farther $1100 \mathrm{~m}$ downslope. Located between 2060 and $1980 \mathrm{~m}$ asl it was $360 \mathrm{~m}$ long. It is the lava flow that spread from this third fissure that is the subject of this case-study.

At 17:45, a GPS coordinate was acquired during a helicopter over flight allowing us to place the flow front at $1.6 \mathrm{~km}$ from the main vent, having advanced down to the $1700 \mathrm{~m}$ asl elevation and meaning that the flow front had advanced at $6.7 \mathrm{~m}$ per minute over the first $4 \mathrm{~h}$ of the eruption. By 18 May it was clear that the belt road was in the path of the flow, with the flow having advanced $3.1 \mathrm{~km}$ in the first $18 \mathrm{~h}$ and now being $4.9 \mathrm{~km}$ short of the road (at $150 \mathrm{~m}$ asl) and $5.9 \mathrm{~km}$ short of the coast. A request thus went out from the OVPF director asking for a risk-assessment to be run regarding the exposure of the road to lava inundation. This request was prompted by the fact that the lava flow was, at that time, moving into a zone known as "Grandes Pentes" (big slopes, Fig. 1b). Here slopes are between 30 and 45\%. In response, FLOWGO was run at all possible TADRs so as to provide a look up table for assessment of risk to the road (Fig. 16). These runs made it clear that the road was in possible danger at the TADRs of that date (10.1 and $21.5 \mathrm{~m}^{3} / \mathrm{s}$, at 09:40 on 19 May), especially if the upper bound applied. There was also a threat to an OPGC permanent monitoring station, station GPSG, where GNSS and a seismometer are operational (Fig. 1). This station was on the predicted path of the flow at a distance of $4.2 \mathrm{~km}$ from the vent and $1.1 \mathrm{~km}$ from the lava flow front position of 18 May at 08:00. It was therefore at risk at TADRs greater than $14 \mathrm{~m}^{3} / \mathrm{s}$. On the basis of precautionary principle, OVPF thus recovered the equipment by a helicopter provided by the Gendarmerie. By the end of the eruption, this branch of the lava flow had stopped less than $150 \mathrm{~m}$ from the station, at which time the station was re-installed.

On 18 May around 08:00, the flows entered a zone of vegetation that extended between 1450 and $1150 \mathrm{~m}$ asl covering an area of $42,500 \mathrm{~m}^{2}$ at a distance between 5 and $4.3 \mathrm{~km}$ west of the road. At this location, the flow front appeared to slow somewhat (despite the mean slope increasing to $40 \%$ ). This was probably due to the effect of the vegetation. In addition, average $\mathrm{SO}_{2}$ fluxes quickly decreased from 2700 tons/day on 18 May to 390 tons/day on 19 May, decreasing more progressively thereafter until 23 May. After 23 May $\mathrm{SO}_{2}$ fluxes were $<80$ tons/day until the end of the eruption. By 21 May, TADRs had also dropped to $2.5 \mathrm{~m}^{3} / \mathrm{s}$ (Fig. 5) so that predicted run-outs reduced to $2 \mathrm{~km}, 6 \mathrm{~km}$ above the road. The eruption ended at 20:50 on 31 May, with the longest-reached flows being $4.05 \mathrm{~km}$ long, having extended to within $3.9 \mathrm{~km}$ of the road.

\section{The response model}

We have reviewed a response model for a crisis at an island volcano that is distant from its administrative center. The model involves synergy between multiple distant nodes so as to create an extended, virtual observatory. At the onset of each eruption the system was triggered by an email from the OVPF director, declaring the date and time of eruption. This was distributed to the email distribution list linking the five institutes involved in this exercise (IPGP, OPGC, LMV, Università di Torino, INGV, Chalmers). Shortly thereafter, the coordinates of

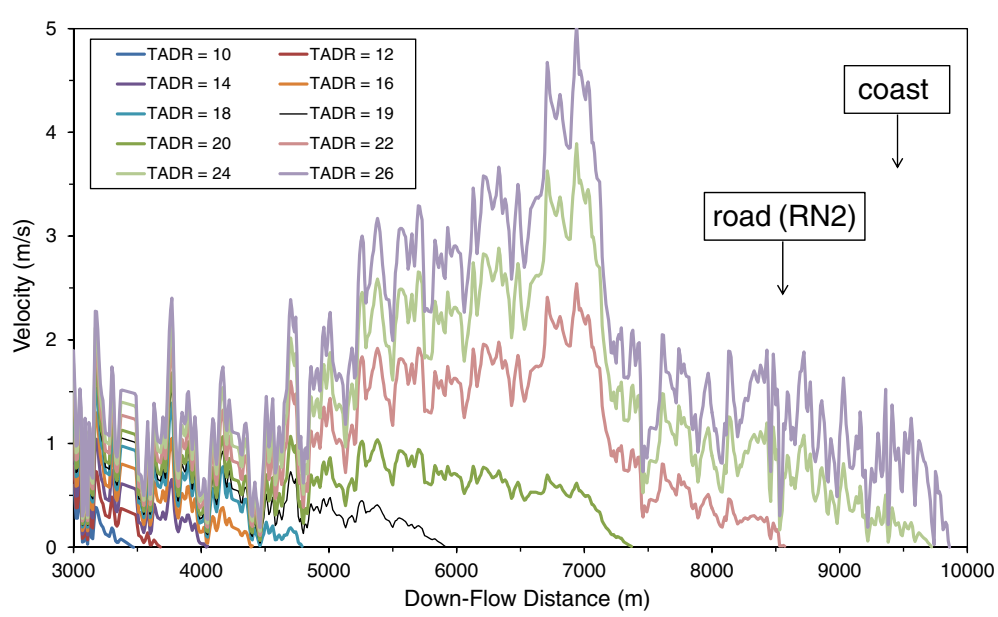

Fig. 16 FLOWGO run, in terms of velocity of lava flowing in the master channel with distance from the vent, using the first TADR values in the range $10-26 \mathrm{~m}^{3} / \mathrm{s}$ down the May 2015 LOSD. This look-up graph shows that the road will likely be attained by channel-fed flow fed at TADRs greater than $22 \mathrm{~m}^{3} / \mathrm{s}$. Any flow fed at TADR exceeding $24 \mathrm{~m}^{3} / \mathrm{s}$ will likely reach the coast 
the vent location were emailed to all partners and DOWNFLOW launched at INGV-Pisa. The output line of steepest descent was then handed on to LMV for initialization of FLOWGO. FLOWGO was then run, and output delivered to OVPF, as soon as the first MIROVAderived TADR arrived (again via email from the Università di Torino to the email distribution list). Initially FLOWGO was run using the chemical model validated for the 2010 eruption, and the magma composition, crystal and vesicle properties of the same eruption. These source terms were then updated upon receipt of first chemical and textural analyses.

In the case reviewed here, the response model was thus based on coordinated and timely input from six different institutions, three of whom were part of the national network charged with formal response (OVPFIPGP, OPGC and LMV), and three of whom were European partners (INGV, Università di Torino, Chalmers University). The flow of source terms, ground truth, product and communication through the system that was developed is given in Fig. 2. Key source terms were vent location, TADR, chemistry, texture, gas fluxes, and temperature LoSD (Table 5) and these were provided by OVPF, Università di Torino, OPGC and Chalmers University. Modeling was then executed by INGV-Pisa and LMV and fed back into the loop. Key to the smooth operation of this system was that information was passed seamlessly between each node, and in the correct order, so as to ensure that products (with known uncertainty) were provided to the observatory director. These information were delivered in a manner and format that was (i) immediately useable, and (ii) trusted. The director was then charged with one-voice communication to the next level in the response chain. The key was that the product had been user-tested, validated and ground-truthed before the crisis, so that useable information (rather than raw data) were provided. Further, the system had sufficient flexibility and communication openness that problems arising during any crisis were clearly communicated, succinctly discussed and then solved in real-time, so that the work flow was modified and evolved as any particular situation evolved.

On the basis of working together during these five effusive crises we can identify five crucial components to ensure smooth information flow: (1) a need for TADR validation; (2) exclusion of fires from satellite signals to isolate the volcanic component; (3) an understanding of lava - vegetation interactions; (4) timely provision and validation of model source terms, and (5) a clear statement of, and if possible a reduction in, uncertainty (including cleaning of data sets of unreliable or untrustworthy data points). One unexpected uncertainty which we encountered was due to sample contamination by the sampling device. Chemical and textural samples critical for source term checking need to be uncontaminated, so we need to find a way to sample without (i) introducing chemical artifacts due to the sampling device, (ii) changing the vesicle structure due to shearing on withdrawal of the sampling device from the fluid, or (iii) from vesiculation during quenching and boiling in water. A realistic sampling protocol also needs to be defined, with no redundancy. That is, if a small, over-worked field- crew charged with monitoring an eruption several kilometers from the nearest vehicle access is to be efficient, then the minimum number of most useful measurements need to be made in a limited amount of time at the most viable (accessible and safe) sites. That is: a realistic and viable sampling protocol needs to be put in place before the crisis.

Table 5 Source terms, ground truth and products, with source, frequency of provision and delivery delay, developed as part the effusive crisis response network of Fig. 13

\begin{tabular}{|c|c|c|c|c|}
\hline Data & Data Type & Source & Frequency of provision & Delay \\
\hline Lava-tephra samples & Sample & In-situ sampling by OVPF staff & $\begin{array}{l}\text { Irregular: } \\
\text { Daily-to-weekly }\end{array}$ & $\begin{array}{l}\text { Days } \\
\text { (delivery time to mainland) }\end{array}$ \\
\hline $\begin{array}{l}\text { Flow dimensions } \\
\text { (flow length, area) }\end{array}$ & Ground-Truth & $\begin{array}{l}\text { Field measurements by OVPF } \\
\text { staff }\end{array}$ & $\begin{array}{l}\text { Irregular: } \\
\text { Daily-to-weekly }\end{array}$ & Hours \\
\hline $\mathrm{SO}_{2}$ flux & Ground-Truth & $\begin{array}{l}\text { Scanning DOAS system } \\
\text { (OVPF) }\end{array}$ & Once every $30 \mathrm{~min}$ & Minutes \\
\hline Vent location \& DEM & Source Term & $\begin{array}{l}\text { GPS \& drone-based } \\
\text { photogrammetry (OVPF) }\end{array}$ & $\begin{array}{l}\text { Irregular: } \\
\text { Daily-to-weekly }\end{array}$ & $\begin{array}{l}\text { Vent location = hours } \\
\text { DEM = days }\end{array}$ \\
\hline $\begin{array}{l}\text { Chemistry, crystallinity } \\
\text { \& vesicularity }\end{array}$ & Source Term \& Product & $\begin{array}{l}\text { Geochemistry and textural } \\
\text { laboratory (OPGC/LMV) }\end{array}$ & Same as sampling & Days-to-weeks \\
\hline TADR & Source Term \& Product & $\begin{array}{l}\text { MIROVA } \\
\text { (Università di Torino) }\end{array}$ & Four times per day & Minutes \\
\hline LOSD & Source Term \& Product & $\begin{array}{l}\text { DOWNFLOW } \\
\text { (INGV-Pisa) }\end{array}$ & $\begin{array}{l}\text { On-demand as vent } \\
\text { locations \& DEM changes }\end{array}$ & Minutes \\
\hline Flow run-outs & Product & $\begin{array}{l}\text { FLOWGO } \\
\text { (LMV) }\end{array}$ & $\begin{array}{l}\text { Four times per day } \\
\text { (as TADR-arrives) }\end{array}$ & Minutes \\
\hline
\end{tabular}




\section{TADR validation}

The best approach to TADR validation is an ensemblebased one that looks for consistency across approaches. In our case the test was:

IF

(1) satellite-based and ground $\mathrm{SO}_{2}$ - and/or IR-derived TADR are in agreement,

\section{AND}

(2)when fed into an appropriately initialized and tested flow model the simulation runs out to field-observed flow lengths

\section{THEN}

the TADR can be trusted.

This is an important need because TADR is intimately related to flow length and area (e.g., Walker 1973; Malin 1980; Pinkerton and Wilson 1994; Calvari and Pinkerton 1998; Murray and Stevens 2000; Harris and Rowland 2009), and hence defines the potential for a lava flow to enter vulnerable areas to cause damage. Collection of field based TADRs are viable, and can be obtained on the basis of thermal emission or flow dynamics from IR cameras. The thermal approach requires a flow-wide thermal mosaic, which requires a platform, such as ultra-light aircraft, helicopter, or drone which may be beyond capacity in terms of funds, weather or technology. The ground-based approach requires set-up of a camera within sight of the master channel to acquire flow dimensions and velocity. Although removing the requirement of a platform, it still means that viewing conditions and geometries have to be opportune, and that a field crew can reach the observation site. At this point, satellite-based methods (validated by occasional field spot checks) appear best suited for rapid response, although the satellite-based measurement has to consistently cross-check with ground truth if it is to be trusted. Inter-validation between satellite and $\mathrm{SO}_{2}$-flux derived TADR is valid only when the pre-eruptive sulfur content is constant. If $\mathrm{SO}_{2}$-derived TADR does not agree with the satellite-based values, but when the latter values provide model-based flow lengths consistent with observed lengths, then we may be able to infer the sulfur output of the erupted lavas.

\section{Problems with fires}

If, as is likely on a heavily vegetated, tropical island volcano, lava ingress into vegetation ignites a fire, then the fire has to be removed from the heat budget if the TADR is not to be over-estimated using the thermal approach. This is an old problem, but solutions are possible using a combination of spectral and field observations, as was the case here. Indeed, separating the intensity, location and spreading direction of a fire from that of the lava is an extremely useful exercise as the fire poses a hazard in its own right. A-priori knowledge of the pre-burn fuel load $\left(\mathrm{kg} \mathrm{m}^{-2}\right)$ will help to estimate the "fire radiative power" (e.g., Van Wagner 1967; Viskanta and Mengüç 1987; Mell et al. 2009), once the fire-affected area is estimated. A map of the potential biomass energy released per unit mass of fully burnt, dry fuel, may thus be useful to correct the radiant power measured by satellite if lava ignites a fire.

\section{Vegetation interaction}

Trees may, or may not, affect lava spreading in terms of both a thermal and mechanical effect. Thermally, a heavily vegetated zone may cause flows to excessively cool and crystalize due to the need to dry and then ignite trees (Van Wagner 1967). Open tree molds may then serve as skylights that allow heat to radiatively escape from the flow interior as is the case for lava tubes (Witter and Harris 2007). The solidification of lava around trees, as well as the trees themselves, then cause mechanical obstructions. Both effects may serve to slow flow advance, but the problem is totally unconstrained.

\section{Provision and validation of model source terms}

Any TADR-derivation model or lava flow simulation model requires input of source terms and validation of output. Crucially this requires data for: chemistry (for the flow viscosity model); eruption temperature (for the flow and TADR model); $\mathrm{SO}_{2}$ gas flux (for TADR validation); flow crystallinity and vesicularity (for the flow and TADR model); plus vent location and up-to-date DEM, with a horizontal and vertical resolution of less than one meter, for flow direction runs. We find use of InSAR data to be extremely promising in this regard.

\section{Perspectives}

The response model described here integrates external partners who need to enter the communication network seamlessly, and provide product that is: (i) trusted and validated, (ii) in a format that is immediately useable, (iii) useful for monitoring and execution of assessment and reporting duties, and (iv) trusted. Within this network, the operation of any methodology, and sources of uncertainty, need to be well-known and spurious (or un-necessary) information removed. Transparency, efficiency and full documentation is thus key. Raw data will not be used, neither will product which is difficult to interpret or whose source is unknown. What are needed are answers, where the observatory will have defined the questions; and it will be up to the partners to iterate on 
their answers until product is seamlessly integrated into the workflow.

A good state-of-the-art example of a similar, but internally-developed, model is that of the HOTSAT system at INGV's Osservatorio Etnea (Ganci et al. 2016). HOTSAT is designed to allow near-real time assessment and simulation of effusive crises at Mount Etna (Sicily, Italy). The system uses satellite (SEVIRI and MODIS) data which are fed into an in-house physics-based lava flow propagation model (MAGFLOW), and is based on detection algorithms (Ganci et al. 2012a, 2012b), TADR conversions (Ganci et al. 2012a, 2012b), and lava flow simulations (Del Negro et al. 2008; Hérault et al. 2009) that have been developed, tested and validated in-house (Vicari et al. 2009), before being launched operationally to allow improved crisis response (Vicari et al. 2011a). The workflow is almost identical to that applied here, where (i) hot pixels are located using satellite data, (ii) the flow model is initialized with a DEM and appropriate chemical and physical volcanological parameters, (iii) the model is executed with vent coordinates and satellitederived TADR, allowing (iv) flow coverage assessments to be delivered for observatory-based hazard assessment purposes (Vicari et al. 2011b). In the case of HOTSAT, the workflow is completed by an observatory-based remote sensing and modeling group which has five members: the same number as the total staff at OVPF charged with monitoring. In our case, the group currently working on the same task (TADR derivation and model execution) does actually number four, but that grouping comes from four institutions in two countries.

Periods of major unrest or high magnitude (explosive) eruptive events have, in the past, prompted assembly of multidisciplinary response teams to support small groups charged with tracking the event. A recent example is the interaction of the UK's Meteorlogical Office and British Geological Survey with the Icelandic Meteorological Office and the Institute of Earth Sciences at the University of Iceland during the 2010 eruption of Eyjafjällajökull (Donovan and Oppenheimer 2012). Such groupings have also been developed, for example, during the eruption of Nevado del Ruiz in 1985 (Hall 1990), at Nyiragongo during and following the 2002 eruption (Allard et al. 2002; Tedesco et al. 2007), and for Merapi in 2010 (Jousset et al. 2012). Another example is the response to eruptive events provided by the USGS Volcano Disaster Assistance Program, which has collaborated with volcano observatories in 12 countries in connection with at least 30 eruptive crises since 1985 (https://volcanoes.usgs.gov/vdap/). In these cases, large international collaborations were configured to assess volcanic activity and their impacts during and following a single event. The case presented in our study differs from these examples in that (i) the collaboration was coordinated from the local volcano observatory, instead of by an external, international (e.g., USGS) or transnational (e.g., UN, VAAC) organization, (ii) our response model is permanent (that is, we activate the model each time there is an eruption), and (iii) the response targets frequent, but low-magnitude eruptive events.

The cases tested here have, instead, been typical, low magnitude effusive events at Piton de la Fournaise with limited (in a geographical sense) impact, with lava flow activity being confined to the Enclos Fouqué caldera. In this case the main causes for concern are (i) burial of the island belt road (RN2), (ii) destruction of observatory instrumentation, (iii) evacuation of the Enclos Fouqué caldera, (iv) security of the footpaths, (v) injury to (and evacuation of) tourists, (vi) fatalities among tourists entering the closed zone, and (vii) forest fires ignited by the active lava. For an eruption in inhabited areas outside of the Enclos Fouqué caldera, including densely populated areas such as around Le Tampon (Fig. 1a), the impact and response model would have to be scaled up, other external participants called, and the component models adjusted to suit, and tested and validated on, the new case. We are currently preparing for such an eventuality through an initiative entitled ANR-LAVA (Lava Advance in Vulnerable Areas). This initiative, funded by the French ANR (Agence National de Recherche), supports the group to develop and test the response model and its component parts, including the simulation model which will be based on that of Bernabeu et al. (2016), for effusive events that enter heavily vegetated and/or populated areas. In such a sensitive case there is even less room for error or mis-communication of uncertainty.

\section{Conclusion}

In France, volcano observatories are dedicated to observations and measurements, plus recording, archiving, communicating and distributing data. During an effusive crisis the observatory director needs to provide local civil protection, and therefore the local municipality, with factual elements that are often quantitative - but always based on trusted measurements. For example, the director needs to support statements such as: "as of 09:45 this-morning discharge rate and flow length was increasing, and the flow front was $5 \mathrm{~km}$ above the road". To answer legitimate questions regarding risk, the director will give responses only based on statistics that have been validated and published with appropriate error bars along with providing possible scenarios based on knowledge of past activity at the volcano. A small staff thus needs all the measurement and model based support that it can obtain, as well as base-line data, in order to support such communications. That support needs to be trusted, timely and, above all, validated. 


\section{Additional file}

Additional file 1: Sample data base with delivery and analysis check-list for all samples collected to track activity at Piton de la Fournaise between 2014 and 2015. Table S1. Sample archive, Part 1: Sample notes and descriptions. Samples are listed in order of eruption, then by order of collection. Eruptions are labelled by date of first sample collection in each case. Table S2. Sample archive, Part 2: Sample collection details. Samples are listed in order of eruption, then by order of collection. Eruptions are labelled by date of first sample collection in each case. Table S3. Sample archive, Part 3: Analysis completed Samples are listed in order of eruption, then by order of collection. Eruptions are labelled by date of first sample collection in each case. G3 = Morphologi G3. (DOCX 125 kb)

\section{Acknowledgments}

We thank two anonymous reviews for their input, and the patience of the Applied Volcanology Editors Office for allowing us two extensions as we were distracted by two eruptive crisis during the submission (31 January - 5 February 2017) and correction (18-19 May 2017) of this manuscript, respectively. We thank the STRAP project funded by the Agence Nationale de la Recherche (ANR-14-CE03-0004-04) and the OMNCG OSU program from la Reunion University for supporting DOAS data acquisition and processing. This work was funded by the Agence National de la Recherche (ANR: www.agence-nationale-recherche.fr) through project ANR-LAVA (ANR Program: DS0902 2016; Project: ANR16 CE39-0009, Pl: A. Harris, Link: www.agence-nationale-recherche.fr/?Projec$\mathrm{t}=\mathrm{ANR}-16-\mathrm{CE} 39-0009)$. This is ANR-LAVA contribution no. 1.

\section{Authors' contributions}

All authors read and approved the final manuscript.

\section{Competing interests}

The authors declare that they have no competing interests

\section{Publisher's Note}

Springer Nature remains neutral with regard to jurisdictional claims in published maps and institutional affiliations.

\section{Author details}

'Université Clermont Auvergne, CNRS, IRD, OPGC, Laboratoire Magmas et Volcans, F-63000 Clermont-Ferrand, France. ${ }^{2}$ Observatoire de Physique du Globe Clermont Ferrand (OPGC), Campus Universitaire des Cézeaux, 4 Avenue Blaise Pascal, TSA 60026 - CS 60026, 63178 Aubière CEDEX, France. ${ }^{3}$ Observatoire Volcanologique du Piton de la Fournaise (OVPF), Institut de Physique du Globe de Paris, Sorbonne Paris Cité, Univ. Paris Diderot, CNRS, F-97418 La Plaine des Cafres, La Réunion, France. ${ }^{4}$ Dipartimento di Scienze della Terra, Università degli Studi di Torino, Via Valperga Caluso 35, 10125 Torino, Italy. ${ }^{5}$ Istituto Nazionale di Geofisica e Vulcanologia (INGV), Via della Faggiola, 32, 56126 Pisa, Italy. 'Department of Space, Earth and Environment, Chalmers University of Technology, SE-412 96 Gothenburg, Sweden.

Received: 27 January 2017 Accepted: 29 May 2017

Published online: 12 June 2017

\section{References}

Allard P, Baxter P, Halbwachs M, Komorowski J-C. Final report of the French-British scientific team: submitted to the Ministry for Foreign Affairs, Paris, France, foreign office, London, United Kingdom and respective embassies in Democratic Republic of Congo and Republic of Rwanda; 2002. p. 24.

Bardolet E, Sheldon PJ. Tourism in archipelagos: Hawai'i and the Balearics. Ann Tour Res. 2008;35(4):900-23.

Bato M, Froger J, Harris A, Villeneuve N. Monitoring an effusive eruption at Piton de la Fournaise using radar and thermal infrared remote sensing data: insights into the October 2010 eruption and its lava flows. In: Harris AJL, De Groeve T, Garel F, Carn SA, editors. Detecting, Modelling and responding to effusive eruptions, vol. 426. London: Geological Society, London, Special Publications; 2016. p. 533-52.

Bello A. Valorisation des eruptions du Piton de la Fournaise, lle de la Réunion. Report to the Parc National de La Réunion (Secteur Est); 2010. p. 25.
Bernabeu N, Saramito C, Smutek C. Modelling lava flow advance using a shallowdepth approximation for three-dimensional cooling of viscoplastic flows. In: Harris AJL, De Groeve T, Garel F, Carn SA, editors. Detecting, Modelling and responding to effusive eruptions, vol. 426. London: Geological Society, London, Special Publications; 2016. p. 409-23.

Boivin P, Bachèlery P. Petrology of 1977 to 1998 eruptions of Piton de la Fournaise, la Réunion Island. J Volcanol Geotherm Res. 2009;184:109-5.

Breaker LC. Estimating and removing sensor-induced correlation from advanced very high resolution radiometer satellite data. J Geophys Res. 1990;95(C6):9601-711.

Brown L. Birth of a mountain: Montserrat's volcano - an eyewitness account. Blackwater: Sargeant Press; 2010. p. 278.

Calder E, Harris A, Peña P, Pilger E, Flynn L, Fuentealba G, et al. Combined thermal and seismic analysis of the Villarrica volcano lava lake, Chile. Rev Geol Chile. 2004;31(2):259-72.

Calvari S, Pinkerton H. Formation of lava tubes and extensive flow field during the 1991-1993 eruption of Mount Etna. J Geophys Res. 1998;B103:27291-301.

Cashman KV, Thornber C, Kauahikaua. Cooling and crystallization of lava in open channels, and the transition of Pāhoehoe lavat O 'A'ã. Bull Volcanol. 1999;61:306-23.

Chester DK, Duncan AM, Dibben CJL. The importance of religion in shaping volcanic risk perception in Italy, with special reference to Vesuvius and Etna. J Volcanol Geotherm Res. 2008;172:216-28.

Colombier M, Gurioli L, Druitt TH, Shea T, Boivin P, Miallier D, et al. Textural evolution ofmagma during the 9.4-ka trachytic explosive eruption at Kilian volcano, Chaîne des Puys, France. Bull Volcanol. 2017;79:17. doi:10.1007/s00445-017-1099-7.

Coppola D, Piscopo D, Staudacher T, Cigolini C. Lava discharge rate and effusive pattern at Piton de la Fournaise from MODIS data. J Volcanol Geotherm Res. 2009;184(1-2):174-92. doi:10.1016/j.jvolgeores.2008.11.031.

Coppola D, James MR, Staudacher T, Cigolini C. A comparison of field- and satellite-derived thermal flux at Piton de la Fournaise: implications for the calculation of lava discharge rate. Bull Volcanol. 2010;72(3):341-56. doi:10. 1007/s00445-009-0320-8.

Coppola D, Laiolo M, Piscopo D, Cigolini C. Rheological control on the radiant density of active lava flows and domes. J Volcanol Geotherm Res. 2013;249: 39-48. doi:10.1016/j.jvolgeores.2012.09.005.

Coppola D, Laiolo M, Cigolini C, Delle Donne D, Ripepe M. Enhanced volcanic hot-spot detection using MODIS IR data: results from the MIROVA system. In: Harris AJL, De Groeve T, Garel F, Carn SA, editors. Detecting, Modelling and responding to effusive eruptions, vol. 426. London: Geological Society, London, Special Publications; 2016. p. 181-205. First published online 14 May 2015. http://doi.org/10.1144/SP426.5.

Coppola D, Di Muro A, Peltier A, Villeneuve N, Ferrazzini V, Favalli M, et al. Shallow system rejuvenation and magma discharge trends at Piton de la Fournaise volcano (la Réunion Island). Earth Planet Sci Lett. 2017;463:13-24.

Dehn J, Dean KG, Engle K, Izbekov P. Thermal precursors in satellite images of the 1999 eruption of Shishaldin volcano. Bull Volcanol. 2002;64:525-45.

Del Negro C, Fortuna L, Herault A, Vicari A. Simulations of the 2004 lava flow at Etna volcano by the MAGFLOWcellular automata model. Bull Volcanol. 2008; 70:805-12. http://doi.org/10.1007/s00445-007-0168-8

Di Muro A, Métrich N, Vergani D, Rosi M, Armienti P, Fougeroux T, et al. The shallow plumbing system of Piton de la Fournaise volcano (la Réunion Island, Indian Ocean) revealed by the major 2007 caldera forming eruption. J Petrol. 2014;55:1287-315.

Di Muro A, Métrich N, Allard P, Aiuppa A, Burton M, Galle B, et al. Magma degassing at Piton de la Fournaise volcano. In: Bachelery P, Lenat J-F, Di Muro A, Michon L, editors. Active volcanoes of the Southwest Indian Ocean. Berlin: Springer; 2016. p. 203-22.

Dietterich HR, Poland MP, Schmidt DA, Cashman KV, Sherrod DR, Espinosa AT. Tracking lava flow emplacement on the east rift zone of Killauea, Hawai'i, with synthetic aperture radar coherence, Geochem. Geophys Geosyst. 2012; 13:Q05001. doi:10.1029/2011GC004016.

Dominey-Howes D, Minos-Minopoulos D. Perceptions of hazard and risk on Santorini. J Volcanol Geotherm Res. 2004;137:285-310.

Donovan A, Oppenheimer C. Governing the lithosphere: Insights from Eyjafjallajökull concerning the role of scientists in supporting decision-making on active volcanoes. J Geophys Res. 2012;117(B03214). doi:10.1029/2011JB009080.

Etcheverria O. Du vignoble à la destination oenotouristique. L'exemple de l'lle de Santorin. Cultur - Revista de Cultura e Turismo. 2014;8(3):188-210.

Favalli M, Pareschi MT, Neri A, Isola I. Forecasting lava flow paths by a stochastic approach. Geophys Res Lett. 2005;32(L03305). doi: 10.1029/2004GL021718.

Frulla LA, Milovich JA, Gagliardini DA. Illumination and observation geometry for NOAA-AVHRR images. Int J Remote Sens. 1995;16(12):2233-53. 
Galle B, Johansson M, Rivera C, Zhang Y, Kihlman M, Kern C, Lehmann T, Platt U, Arellano S, Hidalgo S. Network for Observation of Volcanic and Atmospheric Change (NOVAC)—A global network for volcanic gas monitoring: Network layout and instrument description. J Geophys Res. 2010;115(D05304). doi:10.1029/2009JD011823.

Ganci G, Vicari A, Cappello A, Del Negro C. An emergent strategy for volcano hazard assessment: from thermal satellite monitoring to lava flow modeling, remote Sens. Environment. 2012a;119:197-207. doi:10.1016/j.rse.2011.12.021.

Ganci G, Harris AJL, Del Negro C, Guehenneux Y, Cappello A, Labazuy P, et al. A year of lava fountaining at Etna: volumes from SEVIRI. Geophys Res Lett. 2012b;39:L06305. doi:10.1029/2012GL051026.

Ganci G, Bilotta G, Capello A, Herault A, Del Negro C. HOTSAT: a multiplatform system for the thermal monitoring of volcanic activity using satellite data. In: Harris AJL, De Groeve T, Garel F, Carn SA, editors. Detecting, Modelling and responding to effusive eruptions, vol. 426. London: Geological Society, London, Special Publications; 2016. p. 207-21.

Garau-Vadell JB, Díaz-Armas R, Gutierrez-Taño D. Residents' perceptions of tourism impacts in island destinations: a comparative analysis. Int J Tour Res. 2014;16:578-85.

Garel F, Kaminski E, Tait S, Limare A. An experimental study of the surface thermal signature of hot subaerial isoviscous gravity currents: implications for thermal monitoring of lava flows and domes. J Geophys Res. 2012; 117(B02205). http://dx.doi.org/10.1029/2011JB008698.

Gaudru H. Case study 1: Reunion Island, France - Piton de la Fournaise volcano. In: Erfurt-Cooper P, Cooper M, editors. Volcano and geothermal tourism. London: earthscan; 2010. p. 54-5.

Germanaz C. Du pont des navires au bord des cratères: regards croisés sur le Piton de la Fournaise (1653-1964). Itinéraires iconographiques et essai d'iconologie du volcan actif de La Réunion. Paris: Université Paris-Sorbonne, thèse de doctorat; 2005.

Germanaz C. Le haut lieu touristique comme objet spatial linéaire : le somin Volcan (île de Réunion) Fabrication, banalisation et patrimonialisation. Cahiers de géographie du Québec. 2013;V57(N162):379-405. doi:10.7202/1026525ar.

Gouhier M, Coppola D. Satellite-based evidence for a large hydrothermal system at Piton de la Fournaise volcano. Geophys Res Lett. 2011;38(2):L02302. doi:10. 1029/2010GL046183.

Gouhier M, Guéhenneux Y, Labazuy P, Cacault P, Decriem J, Rivet S. HOTVOLC: a web-based monitoring system for volcanic hot spots. In: Harris AJL, De Groeve T, Garel F, Carn SA, editors. Detecting, modelling and responding to effusive eruptions, vol. 426, The Geological Society of London. London: Geological Society, London, Special Publications; 2016. p. 223-42. doi:10.1144/SP426.31.

Goward SN, Markham B, Dye DG, Dulaney W, Yang J. Normalized difference vegetation index measurements from the advanced very high resolution radiometer. Remote Sens Environ. 1991;35:257-77.

Gurioli L, Andronico D, Bachèlery P, Balcone-Boissard H, Battaglia J, Boudon G, et al. MeMovolc consensual document: a review of cross-disciplinary approaches to characterizing small explosive magmatic eruptions. Bull Volcanol. 2015;77:49. doi:10.1007/s00445-015-0935-x.

Hall M. Chronology of the principal scientific and governmental actions leading up to the November 13, 1985 eruption of Nevado del Ruiz, Colombia. J Volcanol Geotherm Res. 1990;42(1):101-15. doi:10.1016/0377-0273(90)90072-N.

Harris AJL, Baloga S. Lava discharge rates from satellite-measured heat flux. Geophys Res Lett. 2009;36(L19302). doi:10.1029/2009GL039717.

Harris AJL, Rowland SK. FLOWGO: a kinematic thermo-rheological model for lava flowing in a channel. Bull Volcanol. 2001;63:20-44. doi:10.1007/s004450000120.

Harris AJL, Rowland SK. Effusion rate controls on lava flow length and the role of heat loss: a review. In: Thordarson T, Self S, Larsen G, Rowland S K \& Hoskuldsson A, editors. Studies in Volcanology: The Legacy of George Walker. Special Publications of IAVCEI 2; 2009. p. 33-51.

Harris AJL, Keszthelyi L, Flynn LP, Mouginis-Mark PJ, Thornber C, Kauahikaua J, et al. Chronology of the episode 54 eruption at Kilauea volcano, Hawaii, from GOES-9 satellite data. Geophys Res Lett. 1997a;24(24):3281-4.

Harris AJL, Blake S, Rothery DA, Stevens NF. A chronology of the 1991 to 1993 Etna eruption using AVHRR data: implications for real time thermal volcano monitoring. J Geophys Res. 1997b;102(B4):7985-8003.

Harris AJL, Wright R, Flynn LP. Remote monitoring of Mount Erebus Volcano, Antarctica, using polar orbiters: progress and prospects. Int J Remote Sens. 1999;20(15\&16):3051-71.

Harris AJL, Murray JB, Aries SE, Davies MA, Flynn LP, Wooster MJ, et al. Effusion rate trends at Etna and Krafla and their implications for eruptive mechanisms. J Volcanol Geotherm Res. 2000;102(3-4):237-69.

Harris AJL, Pilger E, Flynn LP, Garbeil H, Mouginis-Mark PJ, Kauahikaua J, et al. Automated, high temporal resolution, thermal analysis of Kilauea volcano, Hawaii, using GOES-9 satellite data. Int J Remote Sens. 2001;22(6):945-67.
Harris A, Rhéty M, Gurioli L, Villeneuve N, Paris R. Simulating the thermorheological evolution of channel-contained lava: FLOWGO and its implementation in EXCEL. In: Harris AJL, De Groeve T, Garel F, Carn SA, editors. Detecting, modelling and responding to effusive eruptions, vol. 426. London: Geological Society, London Special Publication; 2016. p. 313-36. doi:10.1144/SP426.9.

Heggie TW. Reported fatal and non-fatal incidents involving tourists in Hawaii volcanoes National Park, 1992-2002. Travel med Infect Dis. 2005;3:123-31.

Heggie TW. Search and Rescue in Alaska's National Parks. Travel med Infect Dis. 2008:6:355-61.

Heggie TW. Death by volcanic laze. Wilderness Environ Med. 2009;20(1):101-3.

Heggie TW, Heggie TM. Viewing lava safely: an epidemiology of hiker injury and illness in Hawaii volcanoes national park. Wilderness Environ Med. 2004;15:77-81.

Heggie TW, Heggie TM. Search and rescue trends and the emergency medical service workload in Utah's national parks. Wilderness Environ Med. 2008;19: 164-71.

Heggie TW, Heggie TM. Search and rescue trends associated with recreational travel in US national parks. J Transl Med. 2009;16(1):23-7.

Hérault A, Vicari A, Ciraudo A, Del Negro C. Forecasting lava flow hazards during the 2006 Etna eruption: using the MAGFLOW cellular automata model. Comput Geosci. 2009;35:1050-60. http://doi.org/10.1016/j.cageo.2007.10.008

Hibert C, Mangeney A, Polacci M, Di Muro A, Vergniolle S, Ferrazzini V, Taisne B, Burton M, Dewez T, Grandjean G, Dupont A, Staudacher T, Brenguier F, Shapiro N.M, Kowalski P, Boissier P, Catherine P, Lauret F (2015) Multidisciplinary monitoring of the January 2010 eruption of Piton de la Fournaise volcano, la Réunion island: J Geophys Res 120: 3026. doi:10.1002/ 2014JB011769.

Holben B, Fraser RS. Red and near-infrared sensor response to off-nadir viewing. Int J Remote Sens. 1984;5(1):145-60.

INSEE. Réunion: Fréquentation touristique 2015 - La frequentation touristique repart à la hausse. La Réunion, St. Denis), No. 16 (Mai 2016): INSEE Analyses; 2016. p. 4.

Jeffreys $\mathrm{H}$. The flow of water in an inclined channel of rectangular section. Philos Mag. 1925:49:793-807.

Josseran L, Paquet C, Zehgnoun A, Caillere N, Le Tertre A, Solet J-L, et al. Chikungunya disease outrbreak, Reunion Island. Emerg Infect Dis. 2006; 12(12):1994-5. doi:10.3201/eid1212.060710.

Jousset S, Pallister J, Boichu M, Buongiorno M, Budisantoso A, Costa F, et al. The 2010 explosive eruption of Java's Merapi volcano-a '100-year' event. J Volcanol Geotherm Res. 2012;241(242):121-35. doi:10.1016/j.jvolgeores.2012.06.018.

Kersten O. Baron Carl Claus von der Decken's Reisen in Ost-Afrika in den jahren 1859 bis 1865 (Vol. 2). Ed Leipzig/Heidelberg: Winterliche Verlagshandlung; 1871.

Kersten O, Tolède M, Fois-Kaschel G (2016). Les Voyages en Afrique orientale du baron Carl Claus von der Decken. : La Réunion (28 mai - 7 août 1863). Les éditions de Villèle; Cercle des Muséophiles de Villèle, 108 p. DOl: 978-2905861-28-3. <hal-01367548>

Kilburn CRJ, Lopes RMC. The growth of aa lava fields on Mount Etna, Sicily. J Geophys Res. 1988;93:14759-72.

L. R. Une trentaine d'interventions pour le SDIS et le PGHM. Le Journal de la lle de La Réunion: Monday 3 August 2015. 2015;21 364:7.

Latutrie B, Harris A, Médard E, Gurioli L. Eruption and emplacement dynamics of a thick trachytic lava flow of the Sancy volcano (France). Bull Volcanol. 2017; 79:4. doi:10.1007/s00445-016-1084-6.

Lillesand TM, Kiefer RW. Remote sensing and image interpretation. New York: Wiley; 1987. p. 24-7.

Llewellin EW, Manga M. Bubble suspension rheology and implications for conduit flow. J Volcanol Geotherm Res. 2005;143:205-17. doi:10.1016/j.jvolgeores.2004.09.018.

Malin MC. Lengths of Hawaiian lava flows. Geology. 1980;8:306-8.

Manga M, Loewenberg M. Viscosity of magmas containing highly deformable bubbles. J Volcanol Geotherm Res. 2001;105:19-24. doi:10.1016/S03770273(00)00239-0.

Markham BL. The Landsat sensors' spatial response. IEEE Trans Geosci Remote Sens. 1985;GE-23:864-75.

Mell W, Maranghides A, McDermott R, Manzello SL. Numerical simulation and experiments of burning douglas fir trees. Combustion and Flame. 2009;156:2023-41.

Michelin Green Guide. La Réunion. Boulonge Billancourt: Le Guide Verte, Michelin Propriétaires-éditeurs; 2015. p. 258.

Michon L, Di Muro A, Villeneuve N, Saint-Marc C, Fadda P, Manta F. Explosive activity of the summit cone of Piton de la Fournaise volcano (la Réunion island): a historical and geological review. J Volcanol Geotherm res. 2013;263:117-33.

Mouginis-Mark PJ, Garbeil H, Flament P. Effects of viewing geometry on AVHRR observations of volcanic thermal anomalies. Remote Sens Environ. 1994;48:51-60. 
Mouginis-Mark PJ, Snell H, Ellisor R. GOES satellite and field observations of the 1998 eruption of Volcan Cerro Azul, Galápagos. Bull Volcanol. 2000;62:188-98.

Murray JB, Stevens N. New formulae for estimating lava flow volumes at Mt. Etna volcano, Sicily. Bull Volcanol. 2000;61:515-26.

Nave R, Ricci T, Pacilli MG. Perception of risk for volcanic hazard in Indian Ocean: la Réunion Island case study. In: Bachelery P, Lenat J-F, Di Muro A, Michon L, editors. Active volcanoes of the Southwest Indian Ocean. Berlin: Springer; 2016. p. 315-26.

Pal R. Rheological behavior of bubble-bearing magmas, Earth Planet. Sci Lett. 2003;207:165-79. doi:10.1016/S0012-821X(02)01104-4.

Payet G. Les Réunionnais et leur Volcan. Antenne Reunionnaise de l'Institute de Victimologie (St Denis, Réunion); 2007. p. 147.

Peltier A, Bachèlery P, Staudacher T. Magma transport and storage at Piton de la Fournaise (la Réunion) between 1972 and 2007: a review of geophysical and geochemical data. J Volcanol Geotherm Res. 2009;184:93-108.

Peltier A, Massin F, Bachèlery P, Finizola A. Internal structures and building of basaltic shield volcanoes : the example of the Piton de la Fournaise terminal cone (la Réunion). Bull Volcanol. 2012;74:1881-97.

Peltier A, Beauducel F, Villeneuve N, Ferrazzini V, Di Muro A, Aiuppa A, et al. Deep fluid transfer evidenced by surface deformation during the 2014-2015 unrest at Piton de la Fournaise volcano. J Volcanol Geotherm Res. 2016;321:140-8. doi:10.1016/j.jvolgeores.2016.04.031.

Perkins MC. Surviving Paradise. USA: Quidnunc Press; 2006. p. 338.

Pieri DC, Baloga SM. Eruption rate, area, and length relationships for some Hawaiian lava flows. J Volcanol Geotherm Res. 1986:30:29-45.

Pinkerton $\mathrm{H}$, Wilson L. Factors effecting the lengths of channel-fed lava flows. Bull Volcanol. 1994;56:108-20.

RED SEED Working Group. Conclusion: recommendations and findings of the RED SEED working group. In: AJL H, De Groeve T, Garel F, Carn SA, editors. Detecting Modelling and responding the effusive eruptions, vol. 426. London: Geological Society London Special Publications; 2016. p. 567-648.

Robert B, Harris A, Gurioli L, Médard E, Sehlke A, Whittington A. Textural and rheological evolution of basalt flowing down a lava channel. Bull Volcanol. 2014;76:824. doi:10.1007/s00445-014-0824-8.

Roscoe R. The viscosity of suspensions of rigid spheres. Br J Appl Phys. 1952;3: 267-9. doi:10.1088/0508-3443/3/8/306

Rudd DR. Remote Sensing: A better view. Belmont: Duxbury Press; 1974. p. 12-3.

Santora M. Réunion, once a surfer's paradise, finds only sharks in its waters. NY: The New York Times (New York Edition), 12 August 2015; 2015. p. A5.

Schmidt A. Volcanic gas and aerosol hazards from a future Laki-type eruption in Iceland. In: Papale P, editor. Volcanic hazards, risks and disasters, hazards and disasters series. Amsterdam: Elsevier; 2015. p. 377-97.

Schowengerdt RA. Remote sensing: models and methods for image processing Burlington: Academic Press; 2007. p. 515.

Silvestre AL, Santos CM, Ramalho C. Satisfaction and behavioural intentions of cruise passengers visiting the Azores. Tour Econ. 2008;14(1):169-84.

Singh SM. Simulation of solar zenith angle effect on global vegetation index (GVI) data. Int J Remote Sens. 1988;9(2):237-48.

Staudacher T, Ferrazzini V, Peltier A, Kowalski P, Boissier P, Catherine $\mathrm{P}$, et al. The April 2007 eruption and the Dolomieu crater collapse, two major events at Piton de la Fournaise (la Réunion Island, Indian Ocean). J Volcanol Geotherm Res. 2009;184:126-37. doi:10.1016/j.jvolgeores.2008.11.005.

Stevenson H. Jobs for the boys: the story of a family in Britain's imperial heyday. Ipswich: Dove Books; 2009. p. 377.

Stewart R. Reunion shark attacks scare surfers and tourists from beaches. The Daily Telegraph; 2015. www.telegraph.co.uk/travel/news/. Downloaded 20/01/17.

Surfer Today. Is there a solution for the shark attack drama in Reunion Island? SurferToday; 2016. mww.surfertoday.com/environment/12880. Downloaded 20/01/17.

Tedesco D, Badiali L, Boschi E, Papale P, Tassi F, Vaselli O, et al. Cooperation on Congo volcanic and environmental risks. Eos, Transactions American Geophysical Union. 2007:88(16):2324-9250. http://dx.doi.org/10.1029/2007EO160001

Tucker CJ, Gatlin JA, Schneider SR. Monitoring vegetation in the Nile delta with NOAA-6 and NOAA-7 AVHRR imagery. Photogramm eng Remote Sens. 1984; 50(1):53-61.

Van Wagner CE. Calculations on forest fire spread by flame radiation. Ottowa: Forestry Branch Departmental Publication 1185, Queen's Printer and Controller of Stationary; 1967. p. 14.

Vaxelaire D. L'histoire de La Réunion 1. Des origines à 1848. Saint-Denis: Édtions Orphie; 2012. p. 350.

Vaxelaire D. L'histoire de La Réunion 2. De 1848 à 2012. Saint-Denis: Édtions Orphie; 2012. p. 703.
Vicari A, Ciraudo A, Del Negro C, Herault A, Fortuna L. Lava flow simulations using discharge rates from thermal infrared satellite imagery during the 2006 Etna eruption. Nat Hazards. 2009;50:539-50. http://doi.org/10.1007/s11069008-9306-7

Vicari A, Ganci G, Behncke B, Cappello A, Neri M, Del Negro C. Near-real-time forecasting of lava flow hazards during the 12-13 January 2011 Etna eruption. Geophys Res Lett. 2011;38:L13317. http://doi.org/10.1029/2011GL047545

Vicari A, Bilotta G, et al. LAV@HAZARD: web-Gis interface for volcanic hazard assessment. Ann Geophys. 2011;54:662-70. http://doi.org/10.4401/ag-5347

Villeneuve N, Neuville DR, Boivin P, Bachèlery P, Richet P. Magma crystallization and viscosity: a study of molten basalts from the Piton de la Fournaise volcano (la Réunion island). Chem Geol. 2008;256:242-51.

Viskanta R, Mengüç MP. Radiation heat transfer in combustion systems. Prog Energy Combust Sci. 1987;13:97-160.

Vlastélic I, Staudacher T, Semet M. Rapid change of lava composition from 1998 to 2002 at Piton de la Fournaise (Réunion) inferred from Pb isotopes and trace elements: evidence for variable crustal contamination. J Petrol. 2005;46: 79-107.

Vlastélic I, Deniel C, Bosq C, Télouk P, Boivin P, Bachèlery P, et al. Pb isotope geochemistry of Piton de la Fournaise historical lavas. J Volcanol Geotherm Res. 2009;184:63-78.

Vlastélic I, Gannoun A, Di Muro A, Gurioli L, Bachèlery P, Henot JM. Origin and fate of sulfide liquids in hotspot volcanism (la Réunion): Pb isotope constraints from residual Fe-cu oxides. Geochim Cosmochim Acta. 2016;194:179-92.

Wadge $\mathrm{G}$. The variation of magma discharge during basaltic eruptions. J Volcanol Geotherm Res. 1981:11:139-68.

Walker GPL. Lengths of lava flows. Philos Trans R Soc Lond. 1973;274:107-18.

Weisel D, Stapleton F. Aloha O Kalapana. Honolulu: Bishop Museum Press; 1992. p. 153.

Witter JB, Harris AJL. Field measurements of heat loss from skylights and lava tube systems. J Geophys Res. 2007;112 (B01203). doi:10.1029/2005JB003800

Wooster MJ, Rothery DA. Time-series analysis of effusive volcanic activity using the ERS along track scanning radiometer: the 1995 eruption of Fernandina volcano, Galápagos Islands. Remote Sens Environ. 1997;62:109-17.

Wooster MJ, Rothery DA, Kaneko T. Geometric considerations for the remote monitoring of volcanoes: studies of lava domes using ATSR and the implications for MODIS. Int J Remote Sens. 1998;19(13):2585-91.

Wright R. MODVOLC: 14 years of autonomous observations of effusive volcanism from space. In: Harris AJL, De Groeve T, Garel F, Carn SA, editors. Detecting, Modelling and responding to effusive eruptions, vol. 426. London: Geological Society, London, Special Publications; 2016. p. 23-53.

Wright R, Blake S, Harris AJL, Rothery DA. A simple explanation for the spacebased calculation of lava eruption rates. Earth Planet Sci Lett. 2001;192:223-33. doi:10.1016/S0012-821X(01)00443-5.

Wright R, Garbeil H, Harris AJL. Using infrared satellite data to drive a thermorheological/stochastic lava flow emplacement model: A method for near-real-time volcanic hazard assessment. Geophys Res Lett. 2008;35(L19307): doi:10.1029/ 2008GL035228.

WTTC. Travel \& Tourism Economic Impact 2015 Reunion. London: Annual Report of the World Travel and Tourism Council; 2015. p. 24.

Zebker HA, Rosen P, Hensley S, Mouginis-Mark PJ. Analysis of active lava flows on Kilauea volcano, Hawaii, using SIR-C radar correlation measurements. Geology. 1996;24:495.

Zhang W, Hu Z, Liu Y, Chen H, Gao S, Gasching RM. Total rock dissolution using ammonium bifluoride (NH4HF2) in screw-top Teflon vials: a new development in open-vessel digestion. Anal Chem. 2012;84:10686-93.

Zinke J, Reijmer JJG, Thomassin BA. Seismic architecture and sediment distribution within the Holocene barrier reef-lagoon complex of Mayotte (Comoro archipelago, SW Indian Ocean). Palaeogeogr Palaeoclimatol Palaeoecol. 2001;175:343-68.

Zuccaro G, Cacace F, Spence RJS, Baxter PJ. Impact of explosive eruption scenarios at Vesuvius. J Volcanol Geotherm Res. 2008;178:416-53. 